Archive for

Organic Chemistry

Arkivoc 2018, part iii, 1-19

\title{
A rapid, efficient and versatile green synthesis of 3,3'-diindolylmethanes
}

\author{
Thanigaimalai Pillaiyar,* Muhammad Dawood, Hina Irum, and Christa E. Müller \\ PharmaCenter Bonn, Pharmaceutical Institute, Pharmaceutical Chemistry I, University of Bonn, \\ An der Immenburg 4, D-53121 Bonn, Germany \\ Email: thanigai@uni-bonn.de
}

Received 07-17-2017

Accepted 10-16-2017

Published on line 11-26-2017

\section{Abstract}

The natural product 3,3'-diindolylmethane (DIM) exhibits anti-cancer and immunostimulatory properties. We report an operationally simple, efficient and versatile synthesis of DIM derivatives by reaction of indoles with aldehydes in the presence of sulfuric acid in water. Short reaction times of only 5 min, simple work-up procedure, avoidance of hazardous organic solvents, and excellent yields are apparent advantages of this method. The synthetic protocol tolerates a broad range of functional groups allowing fast and straightforward access to a large variety of DIM derivatives, including 20 new compounds not previously described in literature, which have potential as anti-cancer drugs.
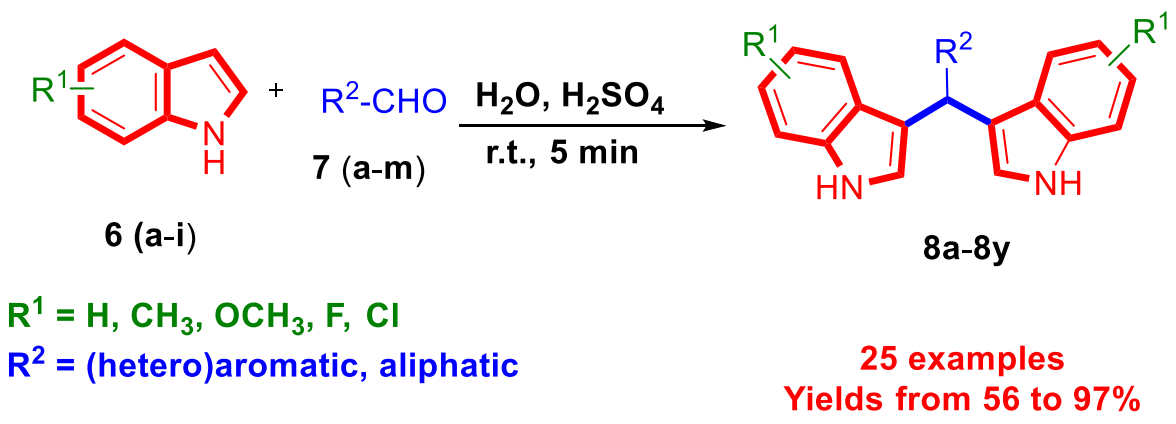

Keywords: Anti-cancer drugs, diindolylmethanes, indole, sulfuric acid, green synthesis 


\section{Introduction}

The indole core is a privileged structure found in biologically active natural products as well as in synthetic drugs. ${ }^{1-3}$ Specifically, diindolylmethanes ${ }^{4}$ and diindolylethanes ${ }^{5}$ are known to possess a wide variety of biological activities including anti-bacterial, ${ }^{6}$ anti-microbial, ${ }^{7}$ anti-fungal ${ }^{8}$ and anti-tumor effects. ${ }^{9}$ For example, vibrindole $A$ (Figure 1A, 1), ${ }^{6}$ isolated from the culture medium of the marine bacterium Vibrio parahemolyticus, and trisindoline (Figure $1 \mathrm{~A}, \mathbf{2}$ ), obtained from the culture of a bacterium Vibrio sp. exhibit anti-biotic activity..$^{10}$ Malassezin (Figure 1A, 3) isolated from the yeast Malassezia furfur ${ }^{11}$ is an agonist of the aryl hydrocarbon receptor (AhR), ${ }^{12}$ a ligand-activated transcription factor associated with gastric carcinogenesis. 3,3'-Diindolylmethane (DIM, 4), which has a skeleton consisting of two indole groups bridged by a single carbon atom at the 3- and $3^{\prime}$ - positions, is a metabolite produced from glucobrassicin, which is found in large amounts in cruciferous vegetables such as broccoli, burssel sprouts and cauliflower. After hydrolysis of glucobrassicin by myrosinase, indole-3-carbinol (IBC) are formed, which then dimerizes to 4 , indolo[3,2-b]carbazole (ICZ, 5) and further products, in the presence of gastric hydrochloric acid (Figure 1B). ${ }^{13}$ It is estimated that approximately $10-20 \%$ of $13 \mathrm{C}$ is metabolized to 4 , and in addition, more than 15 different oligomeric compounds are formed. ${ }^{14}$ Thus, 4 is a major product of $13 \mathrm{C}$ formed in vivo ${ }^{15}$ and therefore the compound has been more extensively investigated than any other $\mathrm{ICC}$ metabolite. ${ }^{16}$ Numerous studies have reported that $\mathbf{4}$ can affect mitogen-activated protein kinase (MAPK), phosphoinositide 3-kinase (PI3K)/Akt and nuclear factor-KB (NF-KB) signaling pathways. ${ }^{17-20}$ It displays anti-inflammatory, ${ }^{19}$ anti-angiogenic, ${ }^{17}$ anticancer, ${ }^{18,20}$ and anti-oxidant activities. ${ }^{21}$ DIM was previously reported to act as an AhR agonist ${ }^{22}$ and to inhibit histone deacetylase-1 (HDAC-1). ${ }^{23}$ Recently DIM and its analogues have been identified and characterized as potent agonists of the immunostimulatory orphan $\mathrm{G}$ protein-coupled receptor GPR84. ${ }^{24,25}$

The goal of the present study was to develop a straightforward access to a broad range of synthetic derivatives and analogues of DIM for subsequent biological studies.

The majority of synthetic methods available for the preparation of DIM derivatives utilizes the FriedelCrafts acylation reaction of indoles with various aldehydes or ketones in the presence of either a Lewis acid (e.g. $\left.\mathrm{AlCl}_{3}, \mathrm{BF}_{3} \cdot \mathrm{Et}_{2} \mathrm{O}\right),{ }^{26}$ protic acids (e.g. $\mathrm{HCl}$, TFA) ${ }^{26}$ metal salts, such as $\operatorname{In}(\mathrm{OTf})_{3}{ }^{26}{ }^{26} \mathrm{Dy}(\mathrm{Otf})_{3}{ }^{26} \operatorname{Ln}(\mathrm{Otf})_{3},{ }^{26}$ $\mathrm{CeCl}_{3} \cdot 7 \mathrm{H}_{2} \mathrm{O},{ }^{26} \mathrm{RuCl}_{3} \cdot 3 \mathrm{H}_{2} \mathrm{O},{ }^{26,27}$ or iodine. ${ }^{26,27}$ The use of solid acidic catalysts ${ }^{28,29}$ such as Amberlyst- $15,{ }^{26}$ montmorillonite clay $\mathrm{K}-10^{26}$ and zeolites $^{26}$ has also been reported. Moreover, benzoic acid, ${ }^{30}$ sodium dodecylsulfate (SDS), ${ }^{31}$ oxalic acid or $\mathrm{N}$-acetyl- $\mathrm{N}, \mathrm{N}, \mathrm{N}$-trimethylammonium bromide (CTAB) in water ${ }^{32}$ were employed for the transformation of indoles to DIMs. Recently, the reaction of indoles, with in situ generated aldehydes from the corresponding alcohols has been reported to obtain DIMs. Examples include an iodinecatalyzed one-pot reaction of benzylic alcohols with indoles, ruthenium(III) chloride trihydrate-catalyzed aerobic oxidation reaction of benzylic alcohols with indoles and $\mathrm{RuCl}_{2}\left(\mathrm{PPh}_{3}\right)_{3} /$ bis-[(2-diphenylphosphanyl)phenyl]ether-catalyzed reaction of benzylic alcohols with indole in the presence of large amount of tripotassium phosphate. ${ }^{33,34}$ Although the reported methodologies are useful, there are still certain drawbacks such as the requirement of expensive catalysts ${ }^{26,35}$ long reaction times ${ }^{36,37}$ formation of hazardous byproducts, harsh reaction condition $\mathrm{s}^{38}$ and complex workup procedures to isolate the products of interest. ${ }^{39}$ In this context, the development of a facile and efficient procedure for the synthesis of diindolylmethanes (DIMs) is highly desirable. 
(A)<smiles>CC(c1c[nH]c2ccccc12)c1c[nH]c2ccccc12</smiles>

Vibrindole A (1)<smiles>O=C1Nc2ccccc2C1C(c1c[nH]c2ccccc12)c1c[nH]c2ccccc12</smiles>

Trisindoline (2)<smiles>O=Cc1c(Cc2c[nH]c3ccccc23)[nH]c2ccccc12</smiles>

Malassezin (3)

(B)

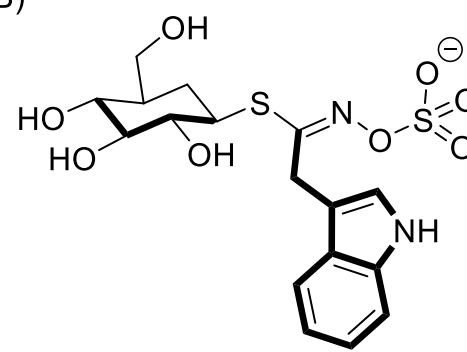

Myrosinase (Cruciferous enzyme)<smiles>OCc1c[nH]c2ccccc12</smiles>
Indole-3-carbinol (I3C)

Glucobrassicin

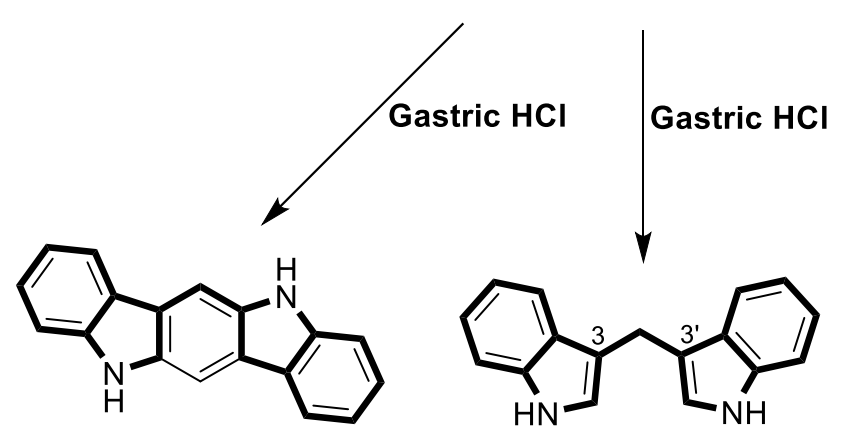

Indolo[3,2-b]carbazole (ICZ, 5)

Diindolylmethane (DIM, 4)

Figure 1. (A) Representative examples of biologically active natural diindolylmethanes (DIMs); (B) Conversion of glucobrassicin to produce DIM (4) and ICZ (5).

\section{Results and Discussion}

Optimization of the reaction conditions. Organic reactions in water as a reaction medium offer many advantages, including low cost, safe handling and environment compatibility. Recently we developed a new procedure for the synthesis of DIMs in aqueous media under microwave irradiation at $100{ }^{\circ} \mathrm{C} .{ }^{25}$ No catalyst was used for the reaction of indoles with formaldehyde, while sodium dodecylsulfate (SDS) was employed as an emulsifier for the reaction of indoles with aliphatic and aromatic aldehydes. ${ }^{25}$

In continuation of our research program, we have now further improved the synthetic access to a large variety of target compounds by developing an operationally simple, fast and efficient green procedure for the synthesis of DIMs.

The reaction of 4-methoxyindole with benzaldehyde (Scheme 1) was tried under a variety of conditions (see Table 1), and considerable variation in yields was observed. 


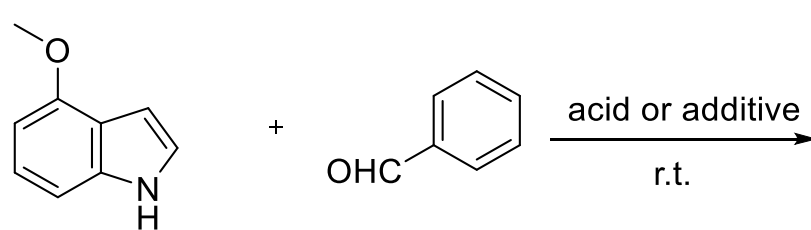

$6 a$

$7 a$

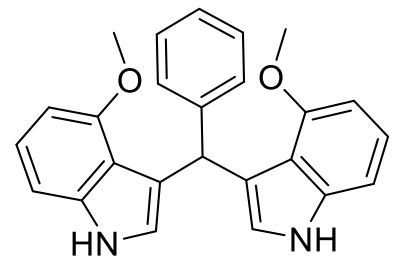

$8 \mathbf{a}$

\section{Scheme 1}

Table 1. Optimization of the reaction conditions ${ }^{\mathrm{a}}$

\begin{tabular}{ccccc}
\hline Entry & Acid or additive (mmol) & Solvent & Reaction time & Yield (\%) ${ }^{\mathrm{b}}$ \\
\hline 1 & concd. $\mathrm{H}_{2} \mathrm{SO}_{4}(2.0)$ & $\mathrm{H}_{2} \mathrm{O}$ & $2 \mathrm{~h}$ & 40 \\
2 & concd. $\mathrm{H}_{2} \mathrm{SO}_{4}(5.0)$ & $\mathrm{H}_{2} \mathrm{O}$ & $30 \mathrm{~min}$ & 87 \\
3 & concd. $\mathrm{H}_{2} \mathrm{SO}_{4}(10)$ & $\mathrm{H}_{2} \mathrm{O}$ & $5 \mathrm{~min}$ & 95 \\
4 & concd. $\mathrm{H}_{2} \mathrm{SO}_{4}(20)$ & $\mathrm{H}_{2} \mathrm{O}$ & $5 \mathrm{~min}$ & 93 \\
5 & concd. $\mathrm{H}_{2} \mathrm{SO}_{4}(10)$ & $\mathrm{DCM}$ & $5 \mathrm{~min}$ & 30 \\
6 & $\mathrm{SDS}(10 \% \mathrm{w} / \mathrm{w})$ & $\mathrm{H}_{2} \mathrm{O}$ & $12 \mathrm{~h}$ & 30 \\
7 & none & $\mathrm{H}_{2} \mathrm{O}$ & $5 \mathrm{~h}$ & 0 \\
8 & $\mathrm{BF}_{3} \cdot \mathrm{Et}_{2} \mathrm{O}(5.0)$ & $\mathrm{DCM}$ & $5 \mathrm{~min}$ & 50 \\
9 & Trifluoroacetic acid (TFA) (5) & $\mathrm{DCM}$ & $24 \mathrm{~h}$ & 25 \\
\hline
\end{tabular}

${ }^{a}$ All the reactions were conducted with 4-methoxyindole $(6 \mathrm{a}, 10 \mathrm{mmol})$, and benzaldehyde $(7 \mathrm{a}, 5 \mathrm{mmol})$ in the presence of acid or additive at room temperature. ${ }^{b}$ Isolated yield.

In order to test this idea, we decided to synthesize DIMs from indoles and aldehydes in the presence of sulfuric acid, which has not been explored well. To the best of our knowledge, only one previous method for the preparation of 3,3'-DIMs in the presence of sulfuric acid in water has been described. ${ }^{15}$ However, the published procedure was carried out under harsh conditions (reaction at $100{ }^{\circ} \mathrm{C}$ for 2.5 to $5 \mathrm{~h}$ ) and suffered in several cases from low yields of less than $20 \%$. Moreover, no efforts to optimize the reaction conditions had been undertaken and the scope of the reaction had not been explored. We therefore systematically studied the reaction conditions by exploring the transformation of 4-methoxyindole $(6 \mathrm{a}, 10 \mathrm{mmol})$ with benzaldehyde (7a, $5 \mathrm{mmol}$ ) yielding 4,4'-dimethoxy-DIM (8a). The reaction was optimized by variation of type and amount of acid and solvent system. In Table 1, entries 1-4, various stoichiometries of sulfuric acid in water as a reaction medium were employed. In the presence of $2 \mathrm{mmol}$ of sulfuric acid the reaction was slow and only $40 \%$ of product was isolated after $2 \mathrm{~h}$, while increasing the amount to 5 or $10 \mathrm{mmol}$ raised product formation to $87 \%$ and $95 \%$, respectively. Reaction in dichloromethane (DCM) was rapid but only $30 \%$ of the desired product was obtained (entry 5). This study suggested that water as a reaction medium increased the yield. Reaction in the presence of SDS (entry 6) was very slow and only $30 \%$ of product was isolated after $12 \mathrm{~h}$. The reaction was not initiated without adding any acid or additive (entry 7). Sulfuric acid was clearly superior to other acids, namely the Lewis acid $\mathrm{BF}_{3} \cdot \mathrm{Et}_{2} \mathrm{O}$ (entry 8 ) or TFA (entry 9). We found sulfuric acid (10 mmol) in water to provide the optimal conditions for the synthesis of 8 a from 4-methoxyindole $(6 a, 10 \mathrm{mmol})$ and benzaldehyde $(7 \mathrm{a}, 5$ mmol), which gave $8 \mathrm{a}$ in $95 \%$ yield.

Substrate scope of the reaction and discussion. We then examined the substrate scope of these optimized reaction conditions with a variety of substituted indoles and aldehydes (see Table 2). It was observed that 
electron-donating substituents or electron-withdrawing substituents on the indole or on the aromatic aldehydes did not significantly impact on the reaction. For example the reaction of 4-methoxybenzaldehyde (7b) or 4-fluorobenzaldehyde (7c) with various substituted indoles afforded the corresponding DIMs in excellent yields of 82 to $96 \%$ (Table 2, compounds $8 \mathbf{8}-8 \mathrm{~h}$ ). We observed that reactions of condensed aromatic aldehydes like naphthalene-1-carboxaldehyde (7d) or naphthalene-2-caboxaldehyde (7e) also proceeded smoothly and resulted in excellent yields of 83 and $89 \%$, respectively (Table 2, compounds $\mathbf{8 i}$ and $\mathbf{8 j}$ ).

Table 2. Reaction of indole derivatives with aliphatic or aromatic aldehydes

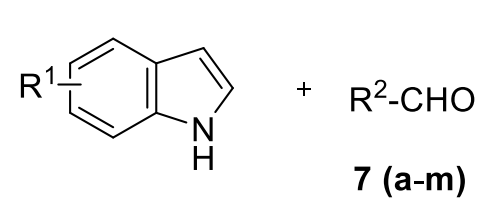

$6(a-i)$

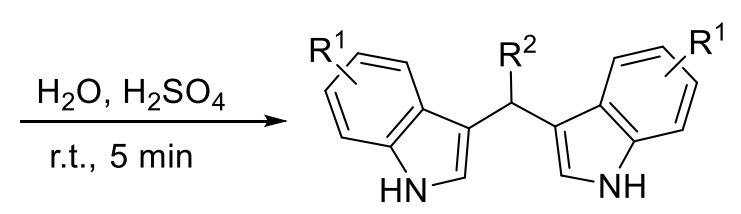

$8(a-x)$

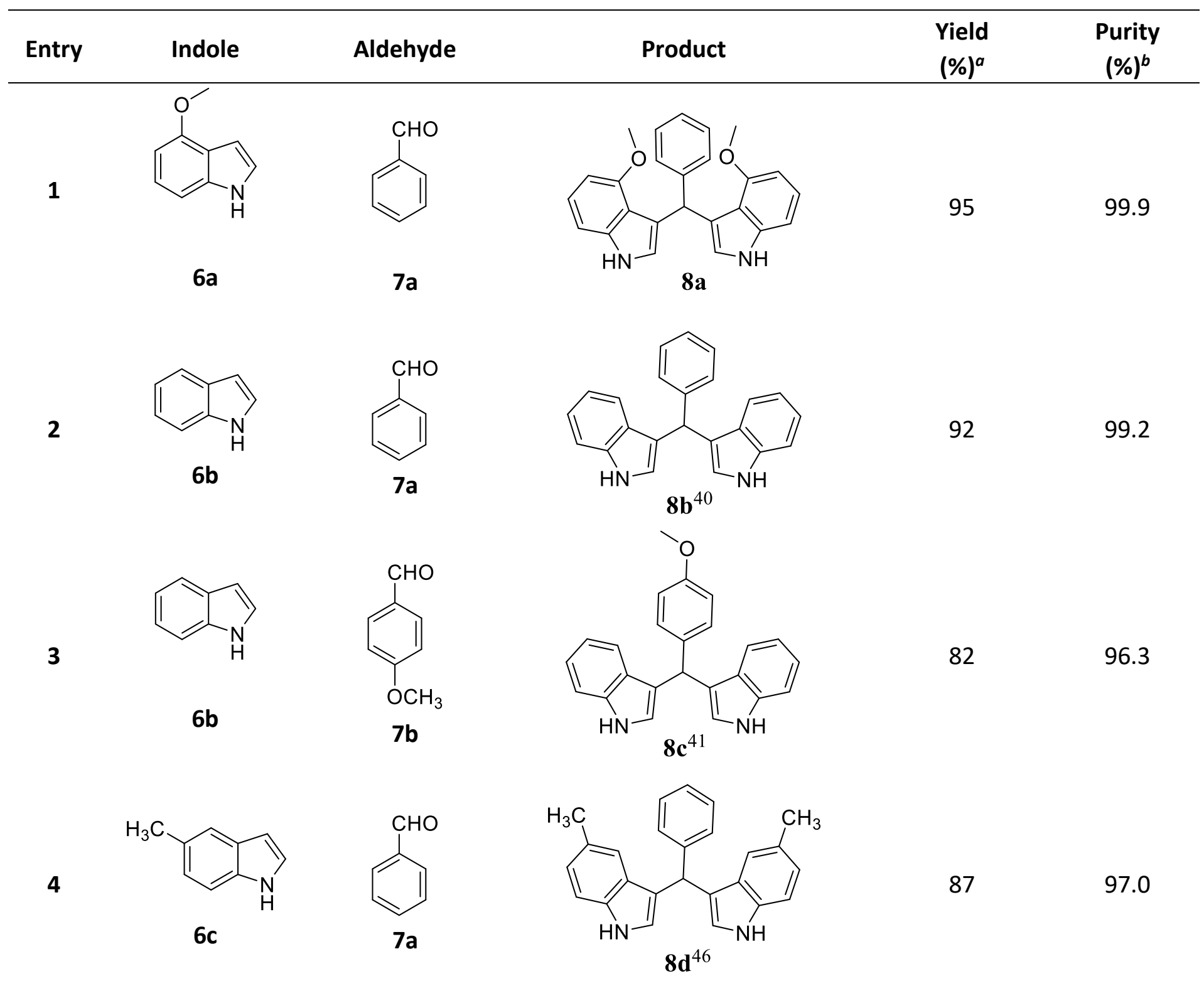


5<smiles>COc1ccc2[nH]ccc2c1</smiles>

6d

6<smiles>Cc1ccc2[nH]ccc2c1</smiles>

6c<smiles>Cc1ccc2[nH]ccc2c1</smiles>

$6 c$<smiles>COc1cccc2[nH]ccc12</smiles>

$6 a$<smiles>COc1cccc2[nH]ccc12</smiles>

$6 a$<smiles>O=Cc1cccc2ccccc12</smiles>

7d<smiles>O=Cc1ccc2ccccc2c1</smiles>

7 e

7c

$7 b$<smiles>Fc1ccc2[nH]ccc2c1</smiles>

$6 e$<smiles>COc1cccc2[nH]cc(C(c3ccc(F)cc3)c3c[nH]c4cccc(OC)c34)c12</smiles><smiles>Cc1ccc2[nH]cc(C(c3ccc(F)cc3)c3c[nH]c4ccc(C)cc34)c2c1</smiles><smiles>Cc1ccc(C(c2c[nH]c3ccc(C)cc23)c2c[nH]c3ccc(C)cc23)cc1</smiles><smiles>COc1ccc(C(c2c[nH]c3cccc(OC)c23)c2c[nH]c3cccc(OC)c23)cc1</smiles>

97.7<smiles>COc1cccc2[nH]cc(C(c3cccc4ccccc34)c3c[nH]c4cccc(OC)c34)c12</smiles>

83<smiles>Fc1ccc2[nH]cc(C(c3ccc4ccccc4c3)c3c[nH]c4ccc(F)cc34)c2c1</smiles>

89 
11<smiles>c1ccc2[nH]ccc2c1</smiles>

$6 b$

12<smiles>Cc1ccc2[nH]ccc2c1</smiles>

$6 c$

13<smiles>c1ccc2[nH]ccc2c1</smiles>

$6 b$

14<smiles>Fc1cccc2[nH]ccc12</smiles>

15<smiles>Fc1ccc2[nH]ccc2c1</smiles>

$6 e$

16<smiles>Fc1ccc2cc[nH]c2c1</smiles>

$6 g$

17<smiles>Fc1cccc2cc[nH]c12</smiles>

6h

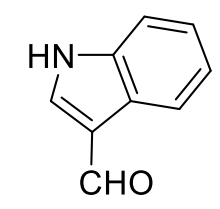

$7 f$

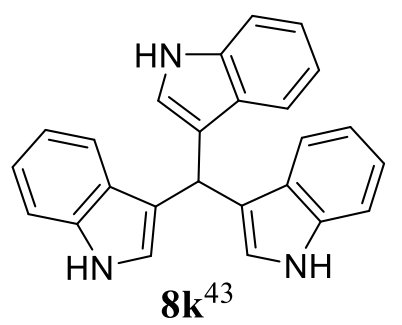<smiles>O=Cc1cccs1</smiles>

$7 \mathrm{~g}$<smiles>O=Cc1ccncc1</smiles>

$7 h$<smiles>Cc1ccc2[nH]cc(C(c3cccs3)c3c[nH]c4ccc(C)cc34)c2c1</smiles>

94

98.2

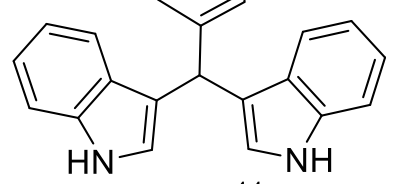

$8 \mathbf{m}^{44}$<smiles>O=Cc1ccncc1</smiles>

7h<smiles>O=Cc1ccncc1</smiles>

$7 h$<smiles>O=Cc1ccncc1</smiles>

$7 \mathrm{~h}$

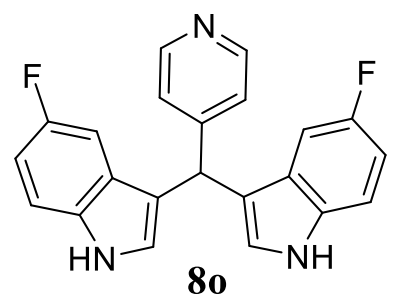

87

98.2

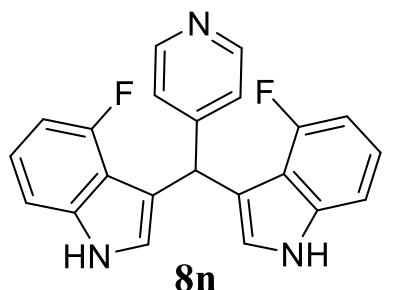

79

97.3

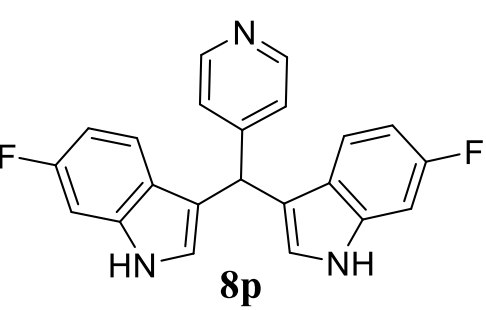

80

77

95.5

96.8

98.5

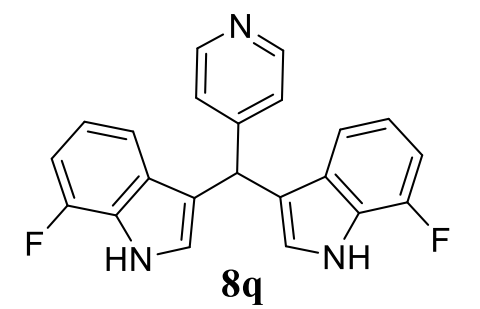


18<smiles>Clc1ccc2[nH]ccc2c1</smiles>

6i<smiles>Fc1ccc2[nH]ccc2c1</smiles>

$6 e$

20<smiles>Fc1cccc2cc[nH]c12</smiles>

$6 \mathrm{~h}$

21<smiles>COc1cccc2[nH]ccc12</smiles>

$6 a$

22<smiles>Cc1ccc2[nH]ccc2c1</smiles>

6c<smiles>Fc1ccc2[nH]ccc2c1</smiles>

$6 e$<smiles>Fc1cccc2[nH]ccc12</smiles>

$6 f$<smiles>O=Cc1ccncc1</smiles>

7h<smiles>CCC=O</smiles>

$7 \mathbf{i}$<smiles>CC(C)C=O</smiles><smiles>CC(C)C=O</smiles><smiles>O=CC1CC1</smiles>

7k<smiles>O=CC1CCCCC1</smiles>

7l<smiles>COC(=O)CCC=O</smiles>

$7 m$<smiles>Clc1ccc2[nH]cc(C(c3ccncc3)c3c[nH]c4ccc(Cl)cc34)c2c1</smiles>

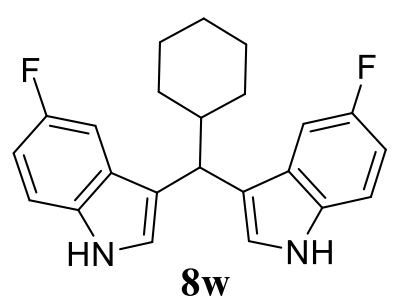

56

96.2 


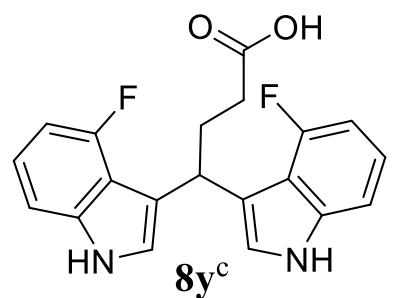

${ }^{a}$ Isolated yields; all isolated products were characterized by ${ }^{1} \mathrm{H} N M R$ and ${ }^{13} \mathrm{C} N M R$, IR and HRMS spectra. In addition, HPLC analysis coupled to electrospray ionization mass spectrometry (LC/ESI-MS) was performed, which was also used to determine the purity of the compounds; ${ }^{b}$ Purity was determined using LC-MS coupled to a UV detector; ${ }^{c}$ Compound $\mathbf{8} \mathbf{y}$ was synthesized by the hydrolysis of $\mathbf{8 x}$.

The synthesis of trisindolylmethane (TIM, 8k) a natural product isolated from the North Sea bacterium Vibrio parahaemolyticus Bio249 was explored. ${ }^{45}$ As indicated in Table 2, 8k was synthesized from $1 \mathrm{H}$-indole (6b) by reaction with indol-3-carbaldehyde (7f) in a high yield of $90 \%$. The efficiency of the new synthetic protocol was further examined by reacting heteroaromatic aldehydes. For example, the reaction of 2 thiophenecarbaldehyde (7g) or 4-pyridinecarbaldehyde (7h) with indoles resulted in high yields of 77 to $94 \%$ (Table 2, compounds $\mathbf{8 I - 8 r}$ ). In order to test the suitability of the procedure for large-scale synthesis, the reaction of $1 \mathrm{H}$-indole $(6 \mathrm{~b}, 42 \mathrm{mmol})$ with 4 -pyridinecarbaldehyde $(7 \mathrm{~g}, 21 \mathrm{mmol})$ was investigated. The reaction afforded $6.5 \mathrm{~g}$ of $\mathbf{8 m}$ in $94 \%$ yield without any significant loss in efficiency. Thus, this synthetic protocol can be used as a practical method to prepare DIM derivatives on a larger scale.

The scope of the reaction was further examined by reacting a variety of aliphatic aldehydes including cyclic aldehydes. The reaction of indoles with non-cyclic aldehydes, for example, propionaldehyde (7i) or isobutyraldehyde (7j), resulted in moderate to good yields of 61 to $72 \%$ (Table 2, compounds $\mathbf{8 s}-\mathbf{8 u}$ ). On the other hand, the reaction of cyclic aldehydes, for example, the reaction of cyclopropanecarbaldehyde (7k) or cyclohexanecarbaldehyde (7I) with indoles gave excellent yields of 83 and $87 \%$, respectively (Table 2 , compounds $\mathbf{8 v}$ and $\mathbf{8 w}$ ). The reaction of an aliphatic aldehyde containing a carboxylic acid ester group was also explored. As indicated in Table 2 , product $\mathbf{8 x}$ was synthesized by reacting methyl 4-oxobutanoate $(\mathbf{7 m})$ with 4fluoroindole (6f). Methyl ester $\mathbf{8 x}$ was subsequently hydrolyzed by treatment with $2 \mathrm{~N}$ sodium hydroxide yielding the corresponding carboxylic acid derivative 8y. In order to compare the efficiency of the new synthetic procedure with that of previously reported reaction conditions, times and yields for the preparation of 3,3'-di-(1H-indolyl)phenylmethane (8b) were compared (Table 3). Moreover the present method used water as a reaction medium which made work-up easy compared to other published procedures (see entry 3 , 4, 6, $910,13,14$, and 15). The reaction mixture was washed with ethyl acetate, dried and evaporated to obtain the desired compounds, which were in most cases purified by recrystallization or by washing with nonpolar solvents. Thus, the present method clearly affords superior results with respect to the employed reagents, solvent, reaction time and eco-friendliness.

Table 3. Comparison of reaction times and yields for the preparation of compound $\mathbf{8 b}$ from indole and benzaldehyde using different reaction conditions

\begin{tabular}{|c|c|c|c|}
\hline Entry & Reactions conditions & Reaction time & $\begin{array}{c}\text { Yield } \\
(\%)\end{array}$ \\
\hline $1^{\mathrm{a}}$ & $\mathrm{H}_{2} \mathrm{SO}_{4}, \mathrm{H}_{2} \mathrm{O}$, r.t. & $5.0 \mathrm{~min}$ & 92 \\
\hline $2^{31}$ & Methanol, r.t. & $18 \mathrm{~h}$ & 78 \\
\hline $3^{26}$ & $\mathrm{CH}_{3} \mathrm{CN}, \mathrm{TCT}$, ${ }^{\mathrm{b}}$ r.t. & $2.0 \mathrm{~h}$ & 90 \\
\hline
\end{tabular}




\begin{tabular}{|c|c|c|c|}
\hline $4^{26}$ & $\mathrm{CH}_{3} \mathrm{CN}, \mathrm{ZrCl}_{4}$, r.t. & $30 \mathrm{~min}$ & 96 \\
\hline $5^{26}$ & Bentonitic clay & $15 \mathrm{~min}$ & 75 \\
\hline $6^{33}$ & $\mathrm{H}_{2} \mathrm{O}$, oxalic acid dihydrate $\left[\left(\mathrm{CO}_{2} \mathrm{H}\right)_{2} \cdot 2 \mathrm{H}_{2} \mathrm{O}\right], \mathrm{CTAB},{ }^{c}$ r.t. & $1.5 \mathrm{~h}$ & 98 \\
\hline $7^{46}$ & $\mathrm{CH}_{2} \mathrm{Cl}_{2}, \mathrm{NaHSO}_{4} \cdot \mathrm{SiO}_{2}$ or Amberlyst-15, r.t. & $2.5 \mathrm{~h}$ & 89 \\
\hline $8^{26}$ & $\mathrm{RuCl}_{3} \cdot 3 \mathrm{H}_{2} \mathrm{O} / \mathrm{C}_{6} \mathrm{H}_{6}$, r.t. & $30 \mathrm{~min}$ & 92 \\
\hline $9^{47}$ & Trityl chloride, r.t. solvent-free & $20 \mathrm{~min}$ & 90 \\
\hline $10^{27}$ & $\mathrm{CH}_{2} \mathrm{Cl}_{2}, \mathrm{PCl}_{5}$, r.t. & $25 \mathrm{~min}$ & 95 \\
\hline $11^{27}$ & $\mathrm{ZrOCl}_{2} \cdot 8 \mathrm{H}_{2} \mathrm{O}$, solvent-free & $40 \mathrm{~min}$ & 84 \\
\hline $12^{26}$ & $\mathrm{CH}_{3} \mathrm{CN}, \ln (\mathrm{OTf})_{3}$ & $25 \mathrm{~min}$ & 71 \\
\hline $13^{48}$ & $\mathrm{EtOH} \cdot \mathrm{H}_{2} \mathrm{O}, \mathrm{Ln}(\mathrm{OTf})_{3}$ & $12 \mathrm{~h}$ & 95 \\
\hline $14^{26}$ & $\mathrm{CH}_{3} \mathrm{CN}$, Zeokarb-225 & $7.5 \mathrm{~h}$ & 95 \\
\hline $15^{49}$ & $\mathrm{CH}_{3} \mathrm{CN}, \mathrm{LiClO}_{4}$ & $2.0 \mathrm{~h}$ & 80 \\
\hline $16^{26}$ & Ionic liquid, Dy(OTf $)_{3}$ & $1.0 \mathrm{~h}$ & 98 \\
\hline $17^{50}$ & AgOTf, & $24 \mathrm{~h}$ & 41 \\
\hline $18^{30}$ & Benzoic acid, $\mathrm{H}_{2} \mathrm{O}, 80^{\circ} \mathrm{C}$ & $15 \mathrm{~h}$ & 80 \\
\hline
\end{tabular}

${ }^{a}$ Present method (in bold); ${ }^{b} \mathrm{TCT}$, trichloro-1,3,5-triazine; ${ }^{c} \mathrm{~N}$-cetyl-N,N,N-trimethylammonium bromide (CTAB).

\section{Conclusions}

We have developed a simple, fast and efficient protocol for the synthesis of diversely substituted 3,3'diindolylmethanes. A series of 25 derivatives was obtained, 20 of which have not been previously reported in literature. The new synthetic protocol offers several advantages including short reaction times, high yields of products, eco-friendliness and simple experimental settings as well as isolation procedures. In addition, this method is highly feasible and applicable to a broad range of aromatic, heteroaromatic and aliphatic aldehydes. It thus provides a convenient access to a large variety of DIM derivatives, which are of great interest due to their exciting biological activities.

\section{Experimental Section}

General. All materials were used as purchased (from Acros, Alfa Aesar, Grüssing, Merck, or Sigma-Aldrich, Germany). Thin-layer chromatography was performed using TLC aluminum silica gel 60 F254 sheets, or TLC aluminum RP silica gel $18 \mathrm{~F}_{254}$ sheets (Merck, Darmstadt, Germany). The purities of isolated products were determined by an LC-MS instrument coupled to electrospray ionization mass spectrometry (LC/ESI-MS) (Applied Biosystems API 2000 LCMS/MS, HPLC Agilent 1100) using the following procedure: the compounds were dissolved at a concentration of $1.0 \mathrm{mg} / \mathrm{mL}$ in acetonitrile, containing $2 \mathrm{mM} \mathrm{CH}_{3} \mathrm{COONH}_{4}$. Then, $10 \mu \mathrm{L}$ of the sample was injected into an HPLC column (Phenomenex Luna $3 \mu \mathrm{C} 18,50 \times 2.00 \mathrm{~mm}$ ). Elution was performed with a gradient of water:methanol (containing $2 \mathrm{mM} \mathrm{CH}_{3} \mathrm{COONH}_{4}$ ) from 90:10 to 0:100 starting the gradient immediately at a flow rate of $250 \mu \mathrm{L} / \mathrm{min}$ for $15 \mathrm{~min}$ followed by washing with $100 \%$ methanol for another $15 \mathrm{~min}$. UV absorption was detected from 200 to $600 \mathrm{~nm}$ using a diode array detector. The purity of the compounds was determined at $254 \mathrm{~nm}$ and was $\geq 95 \%$ for all products. 
${ }^{1} \mathrm{H}$ - and ${ }^{13} \mathrm{C}-\mathrm{NMR}$ data were measured in DMSO- $\mathrm{d}_{6}$ as a solvent. Chemical shifts are reported in parts per million (ppm) relative to the deuterated solvent (DMSO- $\left.d_{6}\right), \delta^{1} \mathrm{H}: 2.49 \mathrm{ppm},{ }^{13} \mathrm{C}: 39.7 \mathrm{ppm}$, coupling constants $\mathrm{J}$ are given in Hertz and spin multiplicities are given as $\mathrm{s}$ (singlet), $\mathrm{d}$ (doublet), $\mathrm{t}$ (triplet), $\mathrm{q}$ (quartet), sext (sextet), $\mathrm{m}$ (multiplet), br (broad). The purities of isolated products were determined by ESI-mass spectra obtained on an HPLC-MS instrument (LC-MS) using the same procedure as previously published. Melting points were measured on a melting point apparatus (Büchi melting point B-545) and are uncorrected.

HRMS was recorded on a micrOTOF-Q mass spectrometer (Bruker) with ESI-source coupled with an HPLC Dionex Ultimate 3000 (Thermo Scientific) using an EC50/2 Nucleodur C18 Gravity $3 \mu \mathrm{m}$ column (MachereyNagel). The column temperature was $425^{\circ} \mathrm{C}$. Ca. $1 \mu \mathrm{L}$ of a $1 \mathrm{mg} / \mathrm{mL}$ solution of the sample in acetonitrile was injected and a flow rate of $0.3 \mathrm{~mL} / \mathrm{min}$ was used. HPLC was started with a solution of acetonitrile in water (10:90), containing $2 \mathrm{mM} \mathrm{CH}_{3} \mathrm{COONH}_{4}$. The gradient was started after 1 min reaching $100 \%$ acetonitrile within $9 \mathrm{~min}$ and then flushed with this concentration for another $5 \mathrm{~min}$. The infrared spectra were recorded as solid samples on an ALPHA-T (Bruker) with a Platinum ATR Module using Opus software. IR spectra were measured in the attenuated total reflection (ATR) mode in the region of $4000-385 \mathrm{~cm}^{-1}$.

\section{General procedure for the synthesis of 3,3'-diindolylmethanes $8 \mathbf{a}-\mathbf{8 x}$}

To the stirred mixture of the appropriate indole (3.1-6.7 mmol) and the appropriate aldehyde (1.5-3.3 mmol, 0.5 equiv.) dissolved in water $(5 \mathrm{~mL})$ concentrated sulfuric acid (1 equiv.) was added. The progress of the reaction was monitored immediately after the addition of $\mathrm{H}_{2} \mathrm{SO}_{4}$ by TLC using ethyl acetate: petroleum ether (20:80). After completion of the reaction as indicated by TLC, the aqueous mixture was dissolved in ethyl acetate and washed with brine. The organic layer was dried over magnesium sulfate, filtered and evaporated to dryness under reduced pressure. The resulting crude product was purified by recrystallization with an appropriate solvent system or by washing it with nonpolar solvents. Few compounds were purified by silica gel column chromatography using non-chlorinated solvent systems such as ethyl acetate: petroleum ether (b.p.42-62 ${ }^{\circ} \mathrm{C}$ ) mixtures $(10: 90$ to $20: 80)$ as eluent to afford the pure diindolylmethane derivatives.

Di-(4-methoxy-1H-indol-3-yl)phenylmethane (8a). 4-Methoxyindole (6a, $0.5 \mathrm{~g}, 3.3 \mathrm{mmol}$ ) was treated with benzaldehyde $(7 \mathrm{a}, 0.180 \mathrm{~mL}, 1.6 \mathrm{mmol}, 0.5$ equiv.) in the presence of concentrated sulfuric acid $(0.181 \mathrm{~mL} ; 3.3$ mol) in water. White solid; m.p. $284-286{ }^{\circ} \mathrm{C}$; yield: $95 \%:{ }^{1} \mathrm{H} \mathrm{NMR}\left(500 \mathrm{MHz}, \mathrm{DMSO}-d_{6}\right) \delta 10.64(\mathrm{~d}, J=2.5 \mathrm{~Hz}, 2 \mathrm{H}$, $2 \times \mathrm{NH}), 7.31-7.13(\mathrm{~m}, 4 \mathrm{H}, 12-\mathrm{H}, 13-\mathrm{H}, 15-\mathrm{H}, 16-\mathrm{H}), 7.13-7.00(\mathrm{~m}, 1 \mathrm{H}, 14-\mathrm{H}), 6.96-6.76\left(\mathrm{~m}, 4 \mathrm{H}, 6-\mathrm{H}, 6-^{\prime} \mathrm{H}, 7-\right.$ $\left.\mathrm{H}, 7^{\prime}-\mathrm{H}\right), 6.66(\mathrm{~s}, 1 \mathrm{H}, 10-\mathrm{H}), 6.53\left(\mathrm{dd}, J=2.3,0.8 \mathrm{~Hz}, 2 \mathrm{H}, 2-\mathrm{H}, 2^{\prime}-\mathrm{H}\right), 6.34$ (dd, J = 6.0, $\left.2.6 \mathrm{~Hz}, 2 \mathrm{H}, 4-\mathrm{H}, 4^{\prime}-\mathrm{H}\right), 3.59$ $\left(\mathrm{s}, 6 \mathrm{H}, 2 \times \mathrm{OCH}_{3}\right) ;{ }^{13} \mathrm{C} \mathrm{NMR}\left(126 \mathrm{MHz}, \mathrm{DMSO}-d_{6}\right) \delta 154.50$ (4-C, 4'-C), 138.08 (9-C, 9'-C), 128.51 (12-C, 16-C), 127.64 (13-C, 15-C), 124.99 (14-C), 122.27 (6-C, 6'-C), 121.66 (2-C, 2'-C), 120.33 (8-C, 8'-C), 116.85 (3-C, 3'-C), 104.86 (7-C, 7'-C), 99.32 (5-C, 5'-C), 55.13 (10-C), 38.03 (2 x OCH OCH $^{\prime}$ : IR 3400, 3343, 3009, 2929, 2839, 1734, 1575, 1433, 1216, 1117, $765 \mathrm{~cm}^{-1}$; LC-MS positive mode: $383(\mathrm{M}+\mathrm{H})^{+}$; purity: 99.9\%. HRMS (ESI-TOF) $\mathrm{m} / \mathrm{z}$ : for $\left(\mathrm{C}_{25} \mathrm{H}_{23} \mathrm{~N}_{2} \mathrm{O}_{2}[\mathrm{M}+\mathrm{H}]^{+}\right)$calcd: 383.1760. Found 383.1754.

Di-(1H-indol-3-yl)phenylmethane (8b). Indole (6b, $0.5 \mathrm{~g}, 4.2 \mathrm{mmol})$ was treated with benzaldehyde (7a, 0.226 $\mathrm{mL}, 2.1 \mathrm{mmol}, 0.5$ equiv.) in the presence of concentrated sulfuric acid $(0.232 \mathrm{~mL}, 4.2 \mathrm{mmol})$ in water. The product was purified by column chromatography. Pale yellow solid; m.p. $145-147$ (lit. m.p.: $\left.146-148{ }^{\circ} \mathrm{C}\right) ;{ }^{40}$ Yield: 92\%; LC-MS, negative mode: $321(\mathrm{M}-\mathrm{H})^{-}$; purity: 99.2\%.

Di-(1H-indol-3-yl)-4-methoxyphenylmethane (8c). Indole (6b, $0.5 \mathrm{~g}, 4.2 \mathrm{mmol})$ was treated with 4-methoxybenzaldehyde (7b, $0.219 \mathrm{~mL}, 2.1 \mathrm{mmol}, 0.5$ equiv.) in the presence of concentrated sulfuric acid $(0.232 \mathrm{~mL}, 4.2$ $\mathrm{mmol}$ ) in water. The product was purified by column chromatography. Brown solid; m.p. $186-188^{\circ} \mathrm{C}$ (lit. m.p.: $\left.188-190{ }^{\circ} \mathrm{C}\right) ;{ }^{41}$ Yield: $82 \%$; LC-MS positive mode $353(\mathrm{M}+\mathrm{H})^{+}$; purity: $96.3 \%$.

Di-(4-methyl-1H-indol-3-yl)phenylmethane (8d). 5-Methylindole (6c, $0.5 \mathrm{~g}, 3.8 \mathrm{mmol})$ was stirred with benzaldehyde $(7 \mathrm{a}, 0.201 \mathrm{~mL}, 1.9 \mathrm{mmol}, 0.5$ equiv.) in the presence of concentrated sulfuric acid $(0.205 \mathrm{~mL}, 3.8$ 
mmol) in water (5.0 mL). Brown solid; m.p. 192-194 (lit. m.p. 193-194 $\left.{ }^{\circ} \mathrm{C}\right)$; $^{42}$ Yield: 87\%; LC-MS, positive mode: $351(\mathrm{M}+\mathrm{H})^{+}$; purity: $97.0 \%$

Di-(4-methoxy-1H-indol-3-yl)-4-fluorophenylmethane (8e). 4-Methoxyindole (6d, $0.5 \mathrm{~g}, 3.3 \mathrm{mmol})$, was stirred with 4-fluorobenzaldehyde $(7 \mathrm{c}, 0.214 \mathrm{~mL}, 1.6 \mathrm{mmol}, 0.5$ equiv.) in the presence of concentrated sulfuric acid $(0.232 \mathrm{~mL}, 4.2 \mathrm{mmol})$ in water. The crude compound was purified by recrystallization using $\mathrm{CHCl}_{3}$; White solid; m.p. $174-176{ }^{\circ} \mathrm{C}$; yield: $96 \%$ : ${ }^{1} \mathrm{H}$ NMR (500 MHz, DMSO-d 6 ) $\delta 10.66$ (d, J=2.4 Hz, $\left.2 \mathrm{H}, 2 \times \mathrm{NH}\right), 7.43$ - $7.12(\mathrm{~m}, 2 \mathrm{H}), 7.07-6.94(\mathrm{~m}, 2 \mathrm{H}), 6.94-6.84(\mathrm{~m}, 4 \mathrm{H}), 6.63(\mathrm{~s}, 1 \mathrm{H}), 6.52\left(\mathrm{dd}, \mathrm{J}=2.4,0.8 \mathrm{~Hz}, 2 \mathrm{H}, 2-\mathrm{H}, 2^{\prime}-\mathrm{H}\right)$, $6.35\left(\mathrm{dd}, J=6.3,2.3 \mathrm{~Hz}, 2 \mathrm{H}, 6-\mathrm{H}, 6^{\prime}-\mathrm{H}\right), 5.74(\mathrm{~s}, 1 \mathrm{H}, 10-\mathrm{H}), 3.59\left(\mathrm{~s}, 6 \mathrm{H}, 2 \times \mathrm{OCH}_{3}\right) ;{ }^{13} \mathrm{C} \mathrm{NMR}\left(126 \mathrm{MHz}, \mathrm{DMSO}-d_{6}\right)$ ठ 154.55 (5-C, 5'-C), 143.66 (11-C), 138.11 (12-C, 16-C), 130.02 (9-C, 9'-C), 129.95 (8-C, 8'-C), 122.25 (2-C, 2'-C), 121.75 (15-C), 120.17 (13-C), 116.75 (7-C, 7'-C), 114.28 (6-C, 6'-C), 114.12 (3-C, 3'-C), 104.89 (4-C, 4'-C), 99.35 (10-C), $55.13\left(2 \times \mathrm{OCH}_{3}\right)$; IR : 3433, 3405, 3009, 2920, 2839, 1734, 1575, 1255, 1081, $765 \mathrm{~cm}^{-1}$; LC-MS, positive mode $401(\mathrm{M}+\mathrm{H})^{+}$; purity: $99.7 \%$. HRMS (ESI-TOF) $\mathrm{m} / \mathrm{z}$ : for $\left(\mathrm{C}_{25} \mathrm{H}_{22} \mathrm{FN}_{2} \mathrm{O}_{2}[\mathrm{M}+\mathrm{H}]^{+}\right)$calcd: 401.1665. Found 401.1660.

Di-(5-methyl-1H-indol-3-yl)-4-fluorophenylmethane (8f). 5-Methylindole (6c, $0.5 \mathrm{~g}, 3.8 \mathrm{mmol}$ ) was stirred with 4-fluorobenzaldehyde (7c, $0.214 \mathrm{~mL}, 1.6 \mathrm{mmol}, 0.5$ equiv.) in the presence of concentrated sulfuric acid $(0.205 \mathrm{~mL}, 3.3 \mathrm{~mol})$ in water $(5.0 \mathrm{~mL})$. The crude compound was purified by recrystallization using $\mathrm{CHCl}_{3} ; \mathrm{Pale}$ yellow solid; m.p. 96-98 ${ }^{\circ} \mathrm{C}$; yield: $93 \%$; ${ }^{1} \mathrm{H} \mathrm{NMR}\left(500 \mathrm{MHz}, \mathrm{DMSO}-\mathrm{d}_{6}\right) \delta 10.63$ (d, J=2.6 Hz, $\left.2 \mathrm{H}, 2 \times \mathrm{NH}\right), 7.40-$ $7.25\left(\mathrm{~m}, 2 \mathrm{H}, 4-\mathrm{H}, 4^{\prime}-\mathrm{H}\right), 7.22\left(\mathrm{~d}, J=8.2 \mathrm{~Hz}, 2 \mathrm{H}, 7-\mathrm{H}, 7^{\prime}-\mathrm{H}\right), 7.12-6.92(\mathrm{~m}, 4 \mathrm{H}, 12-\mathrm{H}, 13-\mathrm{H}, 15-\mathrm{H}, 16-\mathrm{H}), 6.85(\mathrm{dd}$, $\left.J=8.3,1.6 \mathrm{~Hz}, 2 \mathrm{H}, 6-\mathrm{H}, 6^{\prime}-\mathrm{H}\right), 6.69\left(\mathrm{dd}, J=2.4,0.8 \mathrm{~Hz}, 2 \mathrm{H}, 2-\mathrm{H}, 2^{\prime}-\mathrm{H}\right), 5.76(\mathrm{~s}, 1 \mathrm{H}, 10-\mathrm{H}), 2.25\left(\mathrm{~s}, 6 \mathrm{H}, 2 \times \mathrm{CH}_{3}\right) ;{ }^{13} \mathrm{C}$ NMR $\left(126 \mathrm{MHz}, \mathrm{DMSO}-d_{6}\right) \delta 158.44$ (14-C), 135.12 (11-C), 130.04 (9-C, 9'-C), 129.98 (12-C, 16-C), 126.64 (5-C, $\left.5^{\prime}-C\right), 123.76\left(8-C, 8^{\prime}-C\right), 122.66$ (2-C, 2'-C), 118.62 (6-C, 6'-C), 117.67 (4-C, 4'-C), 114.81 (13-C, 15-C), 114.65 (3C, 3'-C), 111.30 (7-C, 7'-C), 58.53 (10-C), 21.39 (2xCH3); IR : 3396, 3015, 2919, 2854, 2839, 1716, 1503, 1418, 1216, 1039, $795 \mathrm{~cm}^{-1}$; LC-MS negative mode 367 (M-H)-; purity: 98.6\%. HRMS (ESI-TOF) $\mathrm{m} / \mathrm{z}$ : for (HRMS (ESITOF) $m / z$ for $\left(\mathrm{C}_{25} \mathrm{H}_{22} \mathrm{FN}_{2}[\mathrm{M}+\mathrm{H}]^{+}\right)$: calcd 369.1767. Found 369.1762.

Di-(5-methyl-1H-indol-3-yl)-4-methoxyphenylmethane (8g). 5-Methylindole (6c, $0.5 \mathrm{~g}, 3.8 \mathrm{mmol})$ was stirred with 4-methoxybenzaldehyde (7b, $0.219 \mathrm{~mL}, 1.9 \mathrm{mmol}, 0.5$ equiv.) in the presence of concentrated sulfuric acid $(0.202 \mathrm{~mL}, 3.7 \mathrm{mmol}, 1$ equiv.) in water $(5.0 \mathrm{~mL})$. The resulting pale brown solid was dissolved in THF and decolorized with charcoal; White solid; m.p. 92-94 ${ }^{\circ} \mathrm{C}$; yield: 89\%: ${ }^{1} \mathrm{H} \mathrm{NMR}\left(500 \mathrm{MHz}, \mathrm{DMSO}-d_{6}\right) \delta 10.58(\mathrm{~d}, J=$ $2.5 \mathrm{~Hz}, 2 \mathrm{H}, 2 \times \mathrm{NH}), 7.21$ (dd, J = 8.5, 3.2 Hz, 4H, 7-H, 7'-H, 4-H, 4'-H), $7.05(\mathrm{q}, J=1.0 \mathrm{~Hz}, 2 \mathrm{H}, 12-\mathrm{H}, 16-\mathrm{H}), 6.90-$ $6.73\left(\mathrm{~m}, 4 \mathrm{H}, 13-\mathrm{H}, 15-\mathrm{H}, 6-\mathrm{H}, 6^{\prime}-\mathrm{H}\right), 6.67\left(\mathrm{dd}, J=2.4,0.9 \mathrm{~Hz}, 2 \mathrm{H}, 2-\mathrm{H}, 2^{\prime}-\mathrm{H}\right), 5.68(\mathrm{~s}, 1 \mathrm{H}, 10-\mathrm{H}), 3.70(\mathrm{~s}, 3 \mathrm{H}$, $\left.\mathrm{OCH}_{3}\right), 2.25\left(\mathrm{~s}, 6 \mathrm{H}, 2 \times \mathrm{CH}_{3}\right) ;{ }^{13} \mathrm{C}$ NMR (126 MHz, DMSO-d 6 ) $\delta 159.10$ (14-C), 137.20 (9-C, 9'-C), 135.13 (3-C, 3'C), 129.25 (12-C, 16-C), 126.98 (11-C), 126.51(5-C, 5'-C), 123.68 (8-C, 8'-C), 122.57 (6-C, 6'-C), 118.72 (4-C, 4'C), $118.16(13-\mathrm{C}, 15-\mathrm{C}), 113.49\left(2-\mathrm{C}, 2^{\prime}-\mathrm{C}\right), 111.25\left(7-\mathrm{C}, 7^{\prime}-\mathrm{C}\right), 55.05\left(\mathrm{OCH}_{3}\right), 21.42\left(2 \times \mathrm{CH}_{3}\right) ; \mathrm{IR}: 3392,3252$, 3055, 2921, 2895, 1716, 1634, 1455, 1418, 1174, $741 \mathrm{~cm}^{-1}$; LC-MS negative mode 379 (M-1H) ${ }^{1-}$; purity: $99.5 \%$. HRMS (ESI-TOF) $m / z$ : for (HRMS (ESI-TOF) $m / z$ : for $\left(\mathrm{C}_{26} \mathrm{H}_{24} \mathrm{~N}_{2} \mathrm{O}\right.$ ) calcd: 380.1889 . Found 380.1883.

Di-(4-methoxy-1H-indol-3-yl)-4-methoxyphenylmethane (8h). 4-Methoxylindole (6a, $0.5 \mathrm{~g}, 3.3 \mathrm{mmol})$ was stirred with 4-methoxybenzaldehyde $(7 \mathbf{b}, 0.224 \mathrm{~mL}, 1.6 \mathrm{mmol}, 0.5$ equiv.) in the presence of concentrated sulfuric acid $\left(0.235 \mathrm{~mL}, 3.3 \mathrm{mmol}, 1\right.$ equiv.) in water $(5.0 \mathrm{~mL})$. White solid; m.p. $230-232{ }^{\circ} \mathrm{C}$; yield: $92 \%$; ${ }^{1} \mathrm{H}$ NMR $(500 \mathrm{MHz}$, DMSO-d 6$) \delta 10.60(\mathrm{~d}, J=2.5 \mathrm{~Hz}, 2 \mathrm{H}, 2 \mathrm{NNH}), 7.21-7.07\left(\mathrm{~m}, 2 \mathrm{H}, 7-\mathrm{H}, 7^{\prime}-\mathrm{H}\right), 6.91-6.85(\mathrm{~m}, 4 \mathrm{H}$, $\left.6-\mathrm{H}, 6^{\prime}-\mathrm{H}, 12-\mathrm{H}, 16-\mathrm{H}\right), 6.83-6.69(\mathrm{~m}, 2 \mathrm{H}, 13-\mathrm{H}, 15-\mathrm{H}), 6.59(\mathrm{~s}, 1 \mathrm{H}, 10-\mathrm{H}), 6.49\left(\mathrm{dd}, J=2.3,0.8 \mathrm{~Hz}, 2 \mathrm{H}, 5-\mathrm{H}, 5^{\prime}-\right.$ $\mathrm{H}), 6.33\left(\mathrm{dd}, J=6.3,2.2 \mathrm{~Hz}, 2 \mathrm{H}, 4-\mathrm{H}, 4^{\prime}-\mathrm{H}\right), 3.68\left(\mathrm{~s}, 3 \mathrm{H}, \mathrm{OCH}_{3}\right), 3.59\left(\mathrm{~s}, 6 \mathrm{H}, 2 \mathrm{xOCH}_{3}\right) ;{ }^{13} \mathrm{C} \mathrm{NMR}(126 \mathrm{MHz}, \mathrm{DMSO})$ $\delta 156.88$ (14-C), 154.64 (4-C, 4'-C), 139.54 (9-C, 9'-C), 138.11 (11-C, 12-C, 16-C), 129.36 (6-C, 6'-C), 122.08 (6-C, 6'-C), 121.62 (2-C, 2'-C), 120.84 (8-C, 8'-C), 116.85 (13-C, 15-C), 113.08 (3-C, 3'-C), 104.84 (7-C, 7'-C), 99.28 (5C, 5'-C), $55.01\left(\mathrm{OCH}_{3}\right), 55.16\left(2 \times \mathrm{OCH}_{3}\right)$; IR : 3440, 3393, 3019, 2927, 2833, 1748, 1609, 1577,1356, 1257, 1115, 
$773 \mathrm{~cm}^{-1}$; LC-MS positive mode: $413(\mathrm{M}+\mathrm{H})^{+}$; purity: 98.2\%. HRMS (ESI-TOF) $\mathrm{m} / z$ : for $\left(\mathrm{C}_{26} \mathrm{H}_{25} \mathrm{~N}_{2} \mathrm{O}_{3}[\mathrm{M}+\mathrm{H}]^{+}\right)$ calcd: 413.1865 . Found 413.1860.

Di-(4-methoxy-1H-indol-3-yl)-1-naphthylmethane (8i). 4-Methoxyindole (6a, $0.5 \mathrm{~g}, 3.3 \mathrm{mmol})$ was treated with naphthalene-1-carboxaldehyde (7d, $0.265 \mathrm{~g}, 1.6 \mathrm{mmol}, 0.5$ equiv.) in the presence of concentrated sulfuric acid (0.186 mL, $3.3 \mathrm{mmol})$ in water $(5.0 \mathrm{~mL})$. White solid; m.p. $256-258{ }^{\circ} \mathrm{C}$; yield: $83 \%$; ${ }^{1} \mathrm{H}$ NMR (500 MHz, DMSO- $\left.d_{6}\right) \delta 10.65(\mathrm{~d}, J=2.5 \mathrm{~Hz}, 2 \mathrm{H}, 2 \times \mathrm{NH}), 8.54-8.10(\mathrm{~m}, 1 \mathrm{H}, 18-\mathrm{H}), 8.02-7.71(\mathrm{~m}, 1 \mathrm{H}, 15-\mathrm{H}), 7.67(\mathrm{~d}$, $J=8.1 \mathrm{~Hz}, 1 \mathrm{H}, 14-\mathrm{H}), 7.52(\mathrm{~s}, 1 \mathrm{H}, 10-\mathrm{H}), 7.50-7.37(\mathrm{~m}, 2 \mathrm{H}, 17-\mathrm{H}, 16-\mathrm{H}), 7.32(\mathrm{dd}, J=8.2,7.2 \mathrm{~Hz}, 1 \mathrm{H}, 13-\mathrm{H})$, $7.14(\mathrm{dd}, J=7.2,1.1 \mathrm{~Hz}, 1 \mathrm{H}, 12-\mathrm{H}), 6.96-6.79\left(\mathrm{~m}, 4 \mathrm{H}, 7-\mathrm{H}, 7^{\prime}-\mathrm{H}, 6-\mathrm{H}, 6^{\prime}-\mathrm{H}\right), 6.49\left(\mathrm{~d}, J=2.3 \mathrm{~Hz}, 2 \mathrm{H}, 2-\mathrm{H}, 2^{\prime}-\mathrm{H}\right)$, $6.41-6.25\left(\mathrm{~m}, 2 \mathrm{H}, 5-\mathrm{H}, 5^{\prime}-\mathrm{H}\right), 3.48\left(\mathrm{~s}, 6 \mathrm{H}, 2 \times \mathrm{OCH}_{3}\right) ;{ }^{13} \mathrm{C}$ NMR (126 MHz, DMSO-d 6 ) $\delta 154.70$ (4-C, 4'-C), 144.04 (9-C, 9'-C) 138.24 (11-C), 133.69 (19-C, 20-C), 131.58 (6-C, 6'-C), 128.31 (15-C), 125.72 (14-C),125.61 (18-C), 125.38 (16-C), 125.04 (17-C), 124.84 (13-C), 124.44 (12-C), 122.96 (2-C, 2'-C), 121.72 (8-C, 8'-C), 119.71 (3-C, 3'-C), 116.79 (7-C, 7-C), 105.01 (5-C, 5'-C), 99.52 (10-C), 55.25 (2 x OCH$)$; IR : 3386, 3057, 2928, 2836, 1613, 1504, 1433, 1332, 1115, 1070, $784 \mathrm{~cm}^{-1}$; LC-MS positive mode: 407 (M+H)+; purity: 97.7\%. (HRMS (ESI-TOF) $\mathrm{m} / \mathrm{z}$ : for $(\mathrm{C} 29 \mathrm{H} 25 \mathrm{~N} 2 \mathrm{O} 2[\mathrm{M}+\mathrm{H}]+)$ calcd: 433.1916. Found 433.1911.

Di-(5-fluoro-1H-indol-3-yl)-2-naphthylmethane (8j). 5-Fluoroindole (6e, $0.5 \mathrm{~g}, 3.6 \mathrm{mmol})$ was treated with naphthalene-2-carboxaldehyde (7e, $0.288 \mathrm{~mL}, 1.8 \mathrm{mmol}, 0.5$ equiv.) in the presence of concentrated sulfuric acid $(0.197 \mathrm{~mL}, 3.6 \mathrm{mmol})$ in water $(5.0 \mathrm{~mL})$. The resulting orange viscous oil was dissolved in THF and decolorized with charcoal. Pale yellow oil; yield: $89 \%$; ${ }^{1} \mathrm{H}$ NMR $\left(500 \mathrm{MHz}, \mathrm{DMSO}-d_{6}\right) \delta 10.96(\mathrm{~d}, \mathrm{~J}=2.5 \mathrm{~Hz}, 2 \mathrm{H}, 2$ $x \mathrm{NH}), 7.92-7.66(\mathrm{~m}, 4 \mathrm{H}, 13-\mathrm{H}, 14-\mathrm{H}, 16-\mathrm{H}, 17-\mathrm{H}), 7.53(\mathrm{dd}, J=8.5,1.8 \mathrm{~Hz}, 1 \mathrm{H}, 15-\mathrm{H}), 7.50-7.40(\mathrm{~m}, 2 \mathrm{H}, 12-$ H, 14'-H), 7.35 (dd, J = 8.8, 4.6 Hz, 2H, 7-H, 7'-H), 6.98 (dd, J=10.1, 2.5 Hz, 4H, 4-H, 4'-H, 2-H, 2'-H), 6.87 (td, J = 9.2, $\left.2.6 \mathrm{~Hz}, 2 \mathrm{H}, 6-\mathrm{H}, 6^{\prime}-\mathrm{H}\right), 5.95(\mathrm{~s}, 1 \mathrm{H}, 10-\mathrm{H}) ;{ }^{13} \mathrm{C}$ NMR (126 MHz, DMSO-d 6 ) $\delta 157.47$ (5-C, $\left.5^{\prime}-\mathrm{C}\right), 142.24(11-\mathrm{C})$, 133.38 (20-C), 133.19 (19-C),131.89 (9-C, 9'C), 127.74 (8-C, 8'-C), 127.70 (12-C), 127.57 (18-C), 127.52 (17-C), 126.97 (13-C), 126.89 (16-C), 126.08 (14-C), 126.00 (15-C), 125.93 (2-C, 2’C), 117.96 (6-C, 6'C), 112.66 (4-C, 4'C), 109.31 (7-C, 7'C), 108.78 (3-C, 3'C), 103.59 (10-C); IR : 3412, 3057, 2923, 2849, 1625, 1579, 1481, 1449, 1116, 1089, 935, $774 \mathrm{~cm}^{-1}$; LC-MS, positive mode: $407(\mathrm{M}+\mathrm{H})^{+}$; purity: 99.6\%. (HRMS (ESI-TOF) m/z for $\left(\mathrm{C}_{27} \mathrm{H}_{18} \mathrm{~F}_{2} \mathrm{~N}_{2} ;+\mathrm{NH}_{4}=\mathrm{C}_{27} \mathrm{H}_{22} \mathrm{~F}_{2} \mathrm{~N}_{3}\right)$ calcd: 426.1782. Found 426.1776.

Tris-(1H-indol-3-yl)methane (8k). Indole (6b, $0.5 \mathrm{~g}, 3.1 \mathrm{mmol})$ was treated with indole-3-carboxaldehyde (7f, $0.170 \mathrm{~g}, 1.5 \mathrm{mmol}, 0.5$ equiv.) in the presence of concentrated sulfuric acid $(0.356 \mathrm{~mL}, 3.1 \mathrm{mmol})$ in water (5.0 $\mathrm{mL}$ ). The resulting yellow solid was dissolved in THF and decolorized with charcoal; White solid; m.p. 245-247 ${ }^{\circ} \mathrm{C}$ (lit. m.p.: $245-249{ }^{\circ} \mathrm{C}$ ); ${ }^{43}$ yield: $90 \%$; LC-MS, positive mode $362(\mathrm{M}+\mathrm{H})^{+}$; purity: 95.5\%.

Di-(5-methyl-1H-indol-3-yl)-2-thienylmethane (8I). 5-Methylindole (6c, $0.5 \mathrm{~g}, 3.8 \mathrm{mmol}$ ) was treated with 2thiophenecarboxaldehyde $(7 \mathrm{~g}, 0.213 \mathrm{~mL}, 1.9 \mathrm{mmol}, 0.5$ equiv.) in the presence of concentrated sulfuric acid $\left(0.202 \mathrm{~mL}, 3.8 \mathrm{mmol}, 1\right.$ equiv.) in water $(5.0 \mathrm{~mL})$. Brown solid; m.p. 85-87 ${ }^{\circ} \mathrm{C}$; yield: $81 \%$; ${ }^{1} \mathrm{H} \mathrm{NMR}(500 \mathrm{MHz}$, DMSO-d 6 ) $\delta 10.65$ (d, J = 2.6 Hz, 2H, $2 \times \mathrm{NH}$ ), 7.27 (dd, $J=5.1,1.3 \mathrm{~Hz}, 1 \mathrm{H}, 14-\mathrm{H}), 7.22\left(\mathrm{~d}, J=8.2 \mathrm{~Hz}, 2 \mathrm{H}, 4-\mathrm{H}, 4^{\prime}-\right.$ H), 7.15 (dd, $\left.J=1.7,0.9 \mathrm{~Hz}, 2 \mathrm{H}, 6-\mathrm{H}, 6^{\prime}-\mathrm{H}\right), 6.93-6.88\left(\mathrm{~m}, 3 \mathrm{H}, 7-\mathrm{H}, 7^{\prime}-\mathrm{H}, 13-\mathrm{H}\right), 6.86(\mathrm{ddd}, J=6.5,2.6,1.4 \mathrm{~Hz}$, $\left.3 \mathrm{H}, 2-\mathrm{H}, 2^{\prime}-\mathrm{H}, 12-\mathrm{H}\right), 6.03(\mathrm{~d}, J=1.0 \mathrm{~Hz}, 1 \mathrm{H}, 10-\mathrm{H}), 2.27\left(\mathrm{~s}, 6 \mathrm{H}, 2 \times \mathrm{CH}_{3}\right) ;{ }^{13} \mathrm{C} \mathrm{NMR}(126 \mathrm{MHz}$, DMSO-d $) \delta 150.70$ (9-C, 9'-C), 135.75 (11-C), 128.35 (5-C, 5'-C), 127.43 (8-C, 8'-C), 127.20 (12-C), 125.38 (13-C), 124.54 (14-C), 124.21 (2-C, 2'-C), 123.42 (6-C, 6'-C), 119.41 (4-C, 4'-C), 118.56 (3-C, 3'-C), 112.08 (7-C, 7'-C), 60.61 (10-C), $22.18\left(2 \times \mathrm{CH}_{3}\right)$; IR: 3410, 3084, 3010, 2915, 2854, 1541, 1480, 1457, 1219, 1090, 859, $720 \mathrm{~cm}^{-1}$; LC-MS, positive mode: $357(\mathrm{M}+\mathrm{H})^{+}$; purity: $96.8 \%$. HRMS (ESI-TOF) $\mathrm{m} / z$ : for $\left(\mathrm{C}_{23} \mathrm{H}_{21} \mathrm{~N}_{2} \mathrm{~S}[\mathrm{M}+\mathrm{H}]^{+}\right.$) calcd: 357.1425 . Found 357.1420.

Di-(1H-indol-3-yl)-4-pyridylmethane $(8 \mathrm{~m})$. Indole $(6 \mathrm{~b}, 5 \mathrm{~g}, 4.2 \mathrm{mmol})$ was treated with 4-pyridinecarboxaldehyde (7h, $1.96 \mathrm{~mL}, 2.1 \mathrm{mmol}, 0.5$ equiv.) in the presence of concentrated sulfuric acid $(2.27 \mathrm{~mL}, 4.2$ mmol, 1 equiv.) in water $(5.0 \mathrm{~mL})$. The resulting pink solid was dissolved in ethanol and decolorized with 
charcoal; White solid; m.p. $157-159{ }^{\circ} \mathrm{C}$ (lit. m.p.: $\left.158-161{ }^{\circ} \mathrm{C}\right) ;{ }^{44}$ yield: $94 \%$; LC-MS, positive mode: $324(\mathrm{M}+\mathrm{H})^{+}$; purity: $98.2 \%$.

Di-(4-fluoro-1H-indol-3-yl)-4-pyridylmethane (8n). 4-Fluoroindole (6f, $0.5 \mathrm{~g}, 3.6 \mathrm{mmol}$ ) was treated with 4-pyridinecarboxaldehyde ( $7 \mathrm{~h}, 0.170 \mathrm{~mL}, 1.8 \mathrm{mmol}, 0.5$ equiv.) in the presence of concentrated sulfuric acid $\left(0.196 \mathrm{~mL}, 3.6 \mathrm{mmol}, 1\right.$ equiv.) in water $(5.0 \mathrm{~mL})$. Orange solid; m.p. $>300{ }^{\circ} \mathrm{C}$; yield: $79 \%$; ${ }^{1} \mathrm{H} \mathrm{NMR}(500 \mathrm{MHz}$, DMSO-d 6$) \delta 11.17(\mathrm{~s}, 2 \mathrm{H}, 2 \times \mathrm{NH}), 8.66-7.92(\mathrm{~m}, 2 \mathrm{H}, 13-\mathrm{H}, 15-\mathrm{H}), 7.28(\mathrm{~d}, J=5.8 \mathrm{~Hz}, 2 \mathrm{H}, 12-\mathrm{H}, 16-\mathrm{H}), 7.19(\mathrm{~d}, J$ $\left.=8.2 \mathrm{~Hz}, 2 \mathrm{H}, 7-\mathrm{H}, 7^{\prime}-\mathrm{H}\right), 7.01\left(\mathrm{td}, J=8.0,5.0 \mathrm{~Hz}, 2 \mathrm{H}, 6-\mathrm{H}, 6^{\prime}-\mathrm{H}\right), 6.72\left(\mathrm{~d}, J=2.4 \mathrm{~Hz}, 2 \mathrm{H}, 5-\mathrm{H}, 5^{\prime}-\mathrm{H}\right), 6.63(\mathrm{dd}, J=$ $\left.11.4,7.8 \mathrm{~Hz}, 2 \mathrm{H}, 2-\mathrm{H}, 2^{\prime}-\mathrm{H}\right), 6.16(\mathrm{~s}, 1 \mathrm{H}, 10-\mathrm{H}) ;{ }^{13} \mathrm{C}$ NMR (126 MHz, DMSO-d 6$) \delta 157.21(4-\mathrm{C}),, 155.40\left(4^{\prime}-\mathrm{C}\right)$, 148.65 (11-C), 139.64 (13-C, 15-C), 139.54 (9-C, 9'-C), 124.57 (12-C, 16-C), 124.01 (2-C, 2'-C), 121.91(6-C, 6'-C), 115.54 (7-C, 7'-C), 115.51 (5-C, 5'-C), 108.27 (3-C, 3'-C), 103.71 (10-C); IR : 3207, 3085, 2999, 1748, 1698, 1634, 1577, 1347, 1224, 1090, $780 \mathrm{~cm}^{-1}$; LC-MS, positive mode: $360(\mathrm{M}+\mathrm{H})^{+}$; purity: $97.3 \%$. HRMS (ESI-TOF) $\mathrm{m} / \mathrm{z}$ : for $\left(\mathrm{C}_{22} \mathrm{H}_{16} \mathrm{~F}_{2} \mathrm{~N}_{3}[\mathrm{M}+\mathrm{H}]^{+}\right)$calcd: 360.1312 . Found 360.1307.

Di-(5-fluoro-1H-indol-3-yl)-4-pyridylmethane (8o). 5-Fluoroindole (6e, 0.5g, $3.6 \mathrm{mmol}$ ) was treated with 4-pyridinecarboxaldehyde ( $7 \mathrm{~h}, 0.170 \mathrm{~mL}, 1.8 \mathrm{mmol}, 0.5$ equiv.) in the presence of concentrated sulfuric acid $(0.196 \mathrm{~mL}, 3.6 \mathrm{mmol}, 1$ equiv.) in water $(5.0 \mathrm{~mL})$. The resulting pink solid was dissolved in ethanol and decolorized with charcoal; Brown solid; m.p. $192-194{ }^{\circ} \mathrm{C}$; yield: 87\%; ${ }^{1} \mathrm{H}$ NMR (500 MHz, DMSO-d $\left.d_{6}\right) 11.23$ (d, J $=3.0 \mathrm{~Hz}, 2 \mathrm{H}, 2 \times \mathrm{NH}), 8.78-8.72(\mathrm{~m}, 2 \mathrm{H}, 13-\mathrm{H}, 15-\mathrm{H}), 7.94-7.89(\mathrm{~m}, 2 \mathrm{H}, 12-\mathrm{H}, 16-\mathrm{H}), 7.38(\mathrm{dd}, J=8.9,4.6 \mathrm{~Hz}$, $\left.2 \mathrm{H}, 7-\mathrm{H}, 7^{\prime}-\mathrm{H}\right), 7.17\left(\mathrm{~d}, J=2.8 \mathrm{~Hz}, 2 \mathrm{H}, 2-\mathrm{H}, 2^{\prime}-\mathrm{H}\right), 7.07$ (dd, J = 9.9, $\left.2.7 \mathrm{~Hz}, 2 \mathrm{H}, 6-\mathrm{H}, 6^{\prime}-\mathrm{H}\right), 6.92(\mathrm{td}, J=9.2,2.7 \mathrm{~Hz}$, $\left.2 \mathrm{H}, 4-\mathrm{H}, 4^{\prime}-\mathrm{H}\right), 6.18(\mathrm{~s}, 1 \mathrm{H}, 10-\mathrm{H}) ;{ }^{13} \mathrm{C}$ NMR (126 MHz, DMSO-d 6 ) $\delta 163.51(5-\mathrm{C}), 157.74\left(5^{\prime}-\mathrm{C}\right), 155.90(11-\mathrm{C})$, 142.45 (13-C, 15-C), 133.30 (9-C, 9'-C), 126.55 (12-C, 16-C), 126.22 (8-C, 8'-C), 124.32 (2-C, 2'-C), 114.99 (6-C, 6'-C), 113.54 (7-C, 7'-C), 112.98 (3-C, 3'-C), 109.40 (4-C, 4'-C), 103.56 (10-C); IR : 3365, 3239, 3064, 1716, 1634, 1486, 1456, 1163, 936, $800 \mathrm{~cm}^{-1}$; LC-MS positive mode: $360(\mathrm{M}+\mathrm{H})^{+}$; purity: $98.2 \%$. HRMS (ESI-TOF) $\mathrm{m} / \mathrm{z}$ : for $\left(\mathrm{C}_{22} \mathrm{H}_{16} \mathrm{~F}_{2} \mathrm{~N}_{3}[\mathrm{M}+\mathrm{H}]^{+}\right)$calcd: 360.1312 . Found 360.1307.

Di-(6-fluoro-1H-indol-3-yl)-4-pyridylmethane (8p). 6-Fluoroindole $(6 \mathrm{~g}, 0.5 \mathrm{~g}, 3.6 \mathrm{mmol})$ was treated with 4-pyridinecarboxaldehyde ( $7 \mathrm{~h}, 0.170 \mathrm{~mL}, 1.8 \mathrm{mmol}, 0.5$ equiv.) in the presence of concentrated sulfuric acid $(0.196 \mathrm{~mL}, 3.6 \mathrm{mmol}, 1$ equiv.) in water $(5.0 \mathrm{~mL})$. The resulting pink solid was dissolved in ethanol and decolorized with charcoal ; White solid d; m.p. $219-221{ }^{\circ} \mathrm{C}$; yield: $80 \%$; ${ }^{1} \mathrm{H}$ NMR (500 MHz, DMSO- $\left.d_{6}\right) \delta 11.15$ $(\mathrm{d}, J=2.5 \mathrm{~Hz}, 2 \mathrm{H}, 2 \times \mathrm{NH}), 8.94-8.19(\mathrm{~m}, 2 \mathrm{H}, 13-\mathrm{H}, 15-\mathrm{H}), 8.13-7.70(\mathrm{~m}, 2 \mathrm{H}, 12-\mathrm{H}, 16-\mathrm{H}), 7.28(\mathrm{dd}, J=8.7,5.4$ $\mathrm{Hz}, 2 \mathrm{H}, 4-\mathrm{H}, 4^{\prime}-\mathrm{H}$ ), 7.15 (dd, J=10.1, $\left.2.4 \mathrm{~Hz}, 2 \mathrm{H}, 7-\mathrm{H}, 7^{\prime}-\mathrm{H}\right), 7.00$ (d, J = 2.4 Hz, 2H, 2-H, 2'-H), 6.78 (ddd, J=9.6, 8.7, $\left.2.4 \mathrm{~Hz}, 2 \mathrm{H}, 5-\mathrm{H}, 5^{\prime}-\mathrm{H}\right), 6.18(\mathrm{~s}, 1 \mathrm{H}, 10-\mathrm{H}) ;{ }^{13} \mathrm{C}$ NMR (126 MHz, DMSO-d 6 ) $\delta 160.01(6-\mathrm{C}), 158.15\left(6^{\prime}-\mathrm{C}\right)$, 142.92 (11-C), 136.51 (13-C, 15-C), 126.13 (9-C, 9'-C), 125.14 (12-C, 16-C), 123.13 (8-C, 8'-C), 119.90 (2-C, 2'-C), 117.33 (7-C, 7'-C), 115.18 (4-C, 4'-C), 107.28 (5-C, 5'-C), 97.89 (10-C); IR : 3734, 3648, 3208, 1716, 1625, 1541, 1456, 1252, 950, $803 \mathrm{~cm}^{-1}$; LC-MS, positive mode: $360(\mathrm{M}+\mathrm{H})^{+}$; purity: $98.5 \%$. HRMS (ESI-TOF) $\mathrm{m} / \mathrm{z}$ : for $\left(\mathrm{C}_{22} \mathrm{H}_{16} \mathrm{~F}_{2} \mathrm{~N}_{3}[\mathrm{M}+\mathrm{H}]^{+}\right)$calcd: 360.1312 . Found 360.1307.

Di-(7-fluoro-1H-indol-3-yl)-4-pyridylmethane (8q). 7-Fluoroindole (6h, 0.5g, $3.6 \mathrm{mmol})$ was treated with 4-pyridinecarboxaldehyde ( $7 \mathrm{~h}, 0.170 \mathrm{~mL}, 1.8 \mathrm{mmol}, 0.5$ equiv.) in the presence of concentrated sulfuric acid $\left(0.196 \mathrm{~mL}, 3.6 \mathrm{mmol}, 1\right.$ equiv.) in water $(5.0 \mathrm{~mL})$. White solid; m.p. $242-244{ }^{\circ} \mathrm{C}$; yield: $77 \%$; $\delta{ }^{1} \mathrm{H} \mathrm{NMR}(500$ $\left.\mathrm{MHz}, \mathrm{DMSO}-d_{6}\right) \delta 11.61(\mathrm{~d}, J=2.5 \mathrm{~Hz}, 2 \mathrm{H}, 2 \times \mathrm{NH}), 8.87-8.53(\mathrm{~m}, 2 \mathrm{H}, 13-\mathrm{H}, 15-\mathrm{H}), 7.98-7.71(\mathrm{~m}, 2 \mathrm{H}, 12-\mathrm{H}$, $16-\mathrm{H}$ ), 7.14 (dd, J = 7.3, $\left.1.3 \mathrm{~Hz}, 2 \mathrm{H}, 4-\mathrm{H}, 4^{\prime}-\mathrm{H}\right), 7.09$ (d, J = 2.5 Hz, 2H, 5-H, 5'-H), $6.96-6.73\left(\mathrm{~m}, 4 \mathrm{H}, 6-\mathrm{H}, 6^{\prime}-\mathrm{H}, 2-\right.$ $\left.\mathrm{H}, 2^{\prime}-\mathrm{H}\right), 6.23(\mathrm{~s}, 1 \mathrm{H}, 10-\mathrm{H}) ;{ }^{13} \mathrm{C}$ NMR $\left(126 \mathrm{MHz}, \mathrm{DMSO}-d_{6}\right) \delta 162.99$ (7-C, 7'-C), 150.38 (13-C, 15-C), 148.44 (11C), 142.64 (9-C, 9'-C), 126.28 (8-C, 8'-C), 125.71 (12-C, 16-C), 119.33 (2-C, 2'-C), 116.00 (4-C, 4'-C), 115.99 (5-C, $\left.5^{\prime}-C\right), 115.13$ (3-C, 3'-C), 106.57 (6-C, 6'-C), 106.47 (10-C); IR : 3208, 3065, 3009, 1748, 1716, 1634, 1576, 1447, 1224, 975, $779 \mathrm{~cm}^{-1}$; LC-MS, positive mode: $360(\mathrm{M}+\mathrm{H})^{+}$; purity: 96.1\%. HRMS (ESI-TOF) m/z: for $\left(\mathrm{C}_{22} \mathrm{H}_{16} \mathrm{~F}_{2} \mathrm{~N}_{3}\right.$ $[\mathrm{M}+\mathrm{H}]^{+}$) calcd: 360.1312 . Found 360.1307 . 
Di-(5-chloro-1H-indol-3-yl)-4-pyridylmethane (8r). 5-Chloroindole (6i, $0.5 \mathrm{~g}, 3.1 \mathrm{mmol}$ ) was treated with 4-pyridinecarboxaldehyde $(7 \mathrm{~g}, 0.168 \mathrm{~mL}, 1.5 \mathrm{mmol}, 0.5$ equiv.) in the presence of concentrated sulfuric acid $(0.356 \mathrm{~mL}, 3.1 \mathrm{mmol})$ in water $(5.0 \mathrm{~mL})$. The resulting pink solid was dissolved in ethanol and decolorized with charcoal; White solid; m.p. 292-294 ${ }^{\circ} \mathrm{C}$; yield: 86\%; ${ }^{1} \mathrm{H}$ NMR $\left(500 \mathrm{MHz}, \mathrm{DMSO}-d_{6}\right) \delta 11.12$ (d, J = 2.6 Hz, $2 \mathrm{H}, 2 \mathrm{x}$ $\mathrm{NH}), 8.53-8.32(\mathrm{~m}, 2 \mathrm{H}, 13-\mathrm{H}, 15-\mathrm{H}), 7.38(\mathrm{~d}, \mathrm{~J}=8.6 \mathrm{~Hz}, 2 \mathrm{H}, 12-\mathrm{H}, 16-\mathrm{H}), 7.34-7.31\left(\mathrm{~m}, 2 \mathrm{H}, 6-\mathrm{H}, 6^{\prime}-\mathrm{H}\right), 7.30(\mathrm{~d}$, $\left.J=2.0 \mathrm{~Hz}, 2 \mathrm{H}, 4^{\prime}-\mathrm{H}, 4^{\prime}-\mathrm{H}\right), 7.04\left(\mathrm{dd}, J=8.6,2.1 \mathrm{~Hz}, 2 \mathrm{H}, 7-\mathrm{H}, 7^{\prime}-\mathrm{H}\right), 6.99\left(\mathrm{~d}, J=2.5 \mathrm{~Hz}, 2 \mathrm{H}, 2^{\prime}-\mathrm{H}, 2^{\prime}-\mathrm{H}\right), 5.90(\mathrm{~s}, 1 \mathrm{H}$, 10-H); ${ }^{13} \mathrm{C}$ NMR (126 MHz, DMSO-d 6 ) $\delta 163.77$ (13-C, 15-C), 142.19 (11-C ), 135.12, (9-C, 9'-C), 127.42,(12-C, 16-C), 126.33 (5-C, 5'-C), 123.60 (8-C, 8'-C), 121.57 (2-C, 2'-C), 121.25 (4-C, 4'-C), 117.95 (6-C, 6'-C), 114.70 (7C, 7'-C), 113.54 (3-C, 3'-C), 113.30 (10-C); IR : 3201, 3076, 2974, 2884, 1632, 1589, 1496, 1347, 1225, 1046, 895, $789 \mathrm{~cm}^{-1}$; LC-MS, positive mode: $393(\mathrm{M}+\mathrm{H})^{+}$; purity: 98.2\%. HRMS (ESI-TOF) $\mathrm{m} / z$ : for $\left(\mathrm{C}_{22} \mathrm{H}_{15} \mathrm{Cl}_{2} \mathrm{~N}_{3}[\mathrm{M}+\right.$ $\mathrm{H}^{+}$) calcd: 392.0712. Found 392.0716.

1,1-Di-(5-fluoro-1H-indol-3-yl)propane (8s). 5-Fluoroindole $(6 \mathrm{e}, 1.0 \mathrm{~g}, 6.7 \mathrm{mmol})$ was treated with propionaldehyde (7i, $0.197 \mathrm{~mL}, 3.3 \mathrm{mmol}, 0.5$ equiv.) in the presence of concentrated sulfuric acid $(0.356 \mathrm{~mL}$, $6.7 \mathrm{mmol})$ in water $(5.0 \mathrm{~mL})$. The resulting green viscous oil was dissolved in THF and decolorized with charcoal ; Yellow viscous oil; yield: 61\%; ${ }^{1} \mathrm{H}$ NMR (600 MHz, DMSO- $\left.d_{6}\right) \delta 10.84$ (d, J = 2.5 Hz, 2H, $2 \times \mathrm{NH}$ ), 7.35 $\left(\mathrm{d}, J=2.4 \mathrm{~Hz}, 2 \mathrm{H}, 2-\mathrm{H}, 2^{\prime}-\mathrm{H}\right), 7.26\left(\mathrm{dd}, J=8.8,4.6 \mathrm{~Hz}, 2 \mathrm{H}, 7-\mathrm{H}, 7^{\prime}-\mathrm{H}\right), 7.14\left(\mathrm{dd}, J=10.3,2.6 \mathrm{~Hz}, 2 \mathrm{H}, 4-\mathrm{H}, 4^{\prime}-\mathrm{H}\right)$, $6.81\left(\mathrm{td}, J=9.2,2.6 \mathrm{~Hz}, 2 \mathrm{H}, 6-\mathrm{H}, 6^{\prime}-\mathrm{H}\right), 4.16(\mathrm{t}, J=7.6 \mathrm{~Hz}, 1 \mathrm{H}, 10-\mathrm{CH}), 2.14\left(\mathrm{p}, J=7.4 \mathrm{~Hz}, 2 \mathrm{H}, 11-\mathrm{CH}_{2}\right), 0.88(\mathrm{t}, J=$ $\left.7.3 \mathrm{~Hz}, 3 \mathrm{H}, 12-\mathrm{CH}_{3}\right) ;{ }^{13} \mathrm{C}$ NMR (151 MHz, DMSO-d 6 ) $\delta 156.63$ (5-C, 5'-C), 133.29 (9-C, 9'-C), 126.94 (8-C, 8'-C), 124.34 (2-C, 2'-C), 118.73 (3-C, 3'-C), 112.27 (6-C, 6'-C), 108.89 (7-C, 7'-C), 108.72 (4-C, 4'-C), 40.11 (10-C), 27.60 (11-C), 13.02 (12-C); IR : 3462, 2420, 2959, 2925, 2869, 1868, 1578, 1480, 1166, 935, $792 \mathrm{~cm}^{-1}$; LC-MS, positive mode: $328\left(\mathrm{M}+\mathrm{H}_{2} \mathrm{O}\right)^{+}$; purity: 98.2\%. HRMS (ESI-TOF) $\mathrm{m} / \mathrm{z}$ : for $\left(\mathrm{C}_{19} \mathrm{H}_{17} \mathrm{~F}_{2} \mathrm{~N}_{2}[\mathrm{M}+\mathrm{H}]^{+}\right)$calcd: 311.1360 Found 311. 1354.

1,1-Di-(7-fluoro-1H-indol-3-yl)-2-methylpropane (8t). 7-Fluoroindole $(6 \mathrm{~h}, 0.5 \mathrm{~g}, 3.6 \mathrm{mmol}$ ) was treated with isobutyraldehyde ( $7 \mathbf{j}, 0.150 \mathrm{~mL}, 1.8 \mathrm{mmol}, 0.5$ equiv.) in the presence of concentrated sulfuric acid $(0.196 \mathrm{~mL}$, $3.6 \mathrm{mmol}$ ) in water $(5.0 \mathrm{~mL})$. The resulting purple colored viscous oil was dissolved in THF and decolorized with charcoal ;Light Brown oil ; yield: 76\%; ${ }^{1} \mathrm{H}$ NMR (500 MHz, DMSO-d $) \delta 11.21$ (d, J=2.2 Hz, $\left.2 \mathrm{H}, 2 \times \mathrm{NH}\right), 7.40$ (d, J $\left.=7.8 \mathrm{~Hz}, 2 \mathrm{H}, 4-\mathrm{H}, 4^{\prime}-\mathrm{H}\right), 7.37\left(\mathrm{~d}, J=2.5 \mathrm{~Hz}, 2 \mathrm{H}, 2-\mathrm{H}, 2^{\prime}-\mathrm{H}\right), 6.90-6.80\left(\mathrm{~m}, 2 \mathrm{H}, 5-\mathrm{H}, 5^{\prime}-\mathrm{H}\right), 6.81-6.73(\mathrm{~m}, 2 \mathrm{H}, 6-\mathrm{H}$, $\left.6^{\prime}-\mathrm{H}\right), 4.09(\mathrm{~d}, J=9.4 \mathrm{~Hz}, 1 \mathrm{H}, 10-\mathrm{H}), 2.76-2.56(\mathrm{~m}, 1 \mathrm{H}, 11-\mathrm{H}), 0.91\left(\mathrm{~d}, J=6.5 \mathrm{~Hz}, 6 \mathrm{H}, 12-\right.$ and $\left.13-\mathrm{CH}_{3}\right) ;{ }^{13} \mathrm{C} \mathrm{NMR}$ $\left(126 \mathrm{MHz}, \mathrm{DMSO}-d_{6}\right) \delta 150.30$ (7-C, 7'-C), 148.38 (9-C, 9'-C), 131.35 (2-C, 2'-C), 123.99 (8-C, 8'-C), 119.22 (5-C, $\left.5^{\prime}-C\right), 118.36$ (4-C, 4'-C), 115.34 (3-C, 3'-C), 115.32 (6-C, 6'-C), 105.54 (10-C), 31.82(12-C), 20.21 (12-and 13-C); IR : 3472, 3419, 2957, 2927, 2868, 1705, 1638, 1497, 1221, $785 \mathrm{~cm}^{-1}$; LC-MS, positive mode: $325(\mathrm{M}+\mathrm{H})^{+}$; purity: 95.2\%. HRMS (ESI-TOF) $m / z$ : for $\left(\mathrm{C}_{20} \mathrm{H}_{19} \mathrm{~F}_{2} \mathrm{~N}_{2} ; \mathrm{NH}_{4}=\mathrm{C}_{20} \mathrm{H}_{22} \mathrm{~F}_{2} \mathrm{~N}_{3}{ }^{+}\right)$calcd: 342. 1782 Found 342. 1776.

1,1-Di-(4-methoxy-1H-indol-3-yl)-2-methylpropane (8u). 4-Methoxyindole (6a, $1.0 \mathrm{~g}, 6.7 \mathrm{mmol}$ ) was treated with isobutyraldehyde (7j, $0.197 \mathrm{~mL}, 3.3 \mathrm{mmol}, 0.5$ equiv.) in the presence of concentrated sulfuric acid ( 0.356 $\mathrm{mL}, 6.7 \mathrm{mmol})$ in water $(10.0 \mathrm{~mL})$. The crude compound purified by recrystallization using $\mathrm{CHCl}_{3}$; White solid; m.p. $189-191^{\circ} \mathrm{C}$; yield: 72\%; ${ }^{1} \mathrm{H}$ NMR (600 MHz, DMSO-d 6$) \delta 10.62$ (d, J = 2.1 Hz, 2H, $\left.2 \times \mathrm{NH}\right), 6.99$ (d, J = $2.4 \mathrm{~Hz}$, $\left.2 \mathrm{H}, 2-\mathrm{H}, 2^{\prime}-\mathrm{H}\right), 6.91-6.80\left(\mathrm{~m}, 4 \mathrm{H}, \mathrm{g}, 6-\mathrm{H}, 6^{\prime}-\mathrm{H}, 7-\mathrm{H}, 7^{\prime}-\mathrm{H}\right), 6.37$ (dd, J = 6.8, $\left.1.7 \mathrm{~Hz}, 2 \mathrm{H}, 5-\mathrm{H}, 5^{\prime}-\mathrm{H}\right), 5.23(\mathrm{~s}, 1 \mathrm{H}, 10-$ $\mathrm{CH}), 3.81\left(\mathrm{~s}, 5 \mathrm{H}, 2 \times \mathrm{OCH}_{3}\right), 2.33(\mathrm{~s}, 1 \mathrm{H}, 11-\mathrm{CH}), 0.86\left(\mathrm{~d}, J=6.6 \mathrm{~Hz}, 6 \mathrm{H}, 12-\mathrm{CH}_{3}\right.$ and $\left.13-\mathrm{CH}_{3}\right) ;{ }^{13} \mathrm{C} \mathrm{NMR}(151 \mathrm{MHz}$, DMSO-d 6 ) $\delta 154.65$ (4-C, 4'-C), 137.57 (9-C, 9'-C), 122.20 (6-C, 6'-C), 121.17 (2-C, 2'-C), 120.20 (8-C, 8'-C), 117.62 (3-C, 3'-C), $104.73\left(7-C, 7^{\prime}-C\right), 98.81\left(5-C, 5^{\prime}-C\right), 54.86(10-C), 40.11\left(2 \times \mathrm{OCH}_{3}\right), 21.70$ (11-C), 14.30 (12-C, 13-C). IR : 3388, 3300, 2923, 2853, 1717, 1614, 1575, 1507, 1349, 1252, 1069, 968, $774 \mathrm{~cm}^{-1}$; LC-MS, positive mode $328\left(\mathrm{M}+\mathrm{H}_{2} \mathrm{O}\right)^{+}$; purity: 95.2\%. HRMS (ESI-TOF) $\mathrm{m} / z$ : for $\left(\mathrm{C}_{22} \mathrm{H}_{25} \mathrm{~N}_{2} \mathrm{O}_{2}\left[\mathrm{M}+\mathrm{H}^{+}\right)\right.$calcd: 349.1916 Found 349.1911. 
(Cyclopropyl)di-(5-methyl-1H-indol-3-yl)methane (8v). 5-Methylindole (6c, $0.5 \mathrm{~g}, 3.8 \mathrm{mmol})$ was stirred with cyclopropanecarboxaldehyde (7k, $0.143 \mathrm{~mL}, 1.9 \mathrm{mmol}, 0.5$ equiv.) in the presence of concentrated sulfuric acid (0.202 mL, $3.8 \mathrm{mmol}, 1$ equiv.) in water (5.0 mL). Brown solid; m.p. 164-166 ${ }^{\circ} \mathrm{C}$; yield: $83 \%$; ${ }^{1} \mathrm{H}$ NMR (500 $\left.\mathrm{MHz}, \mathrm{DMSO}-d_{6}\right) \delta 10.85$ (br s, 2H, $\left.2 \times \mathrm{NH}\right), 7.29-6.98\left(\mathrm{~m}, 6 \mathrm{H}, 4-\mathrm{H}, 4^{\prime}-\mathrm{H}, 6-\mathrm{H}, 6^{\prime}-\mathrm{H}, 7-\mathrm{H}, 7^{\prime}-\mathrm{H}\right), 6.79$ (dd, J=8.2, $\left.1.6 \mathrm{~Hz}, 2 \mathrm{H}, 2-\mathrm{H}, 2^{\prime}-\mathrm{H}\right), 3.71(\mathrm{~d}, J=8.6 \mathrm{~Hz}, 1 \mathrm{H}, 10-\mathrm{H}), 2.25\left(\mathrm{~s}, 6 \mathrm{H}, 2 \times \mathrm{CH}_{3}\right), 1.59$ (qt, J = 8.1, $\left.4.9 \mathrm{~Hz}, 1 \mathrm{H}, 11-\mathrm{H}\right)$, $0.64-0.38\left(\mathrm{~m}, 2 \mathrm{H}, 12-\mathrm{CH}_{2}\right), 0.33-0.16\left(\mathrm{~m}, 2 \mathrm{H}, 13-\mathrm{CH}_{2}\right) .{ }^{13} \mathrm{C}$ NMR (126 MHz, DMSO- $\left.d_{6}\right) \delta 135.00\left(9-\mathrm{C}, 9^{\prime}-\mathrm{C}\right)$, 127.22 (5-C, 5'-C), 126.15 (8-C, 8'-C), 122.45 (2-C, 2'-C), 122.24 (6-C, 6'-C), 118.86 (4-C, 4'-C), 118.20 (3-C, 3'-C), 111.10 (7-C, 7'-C), $37.91(10-\mathrm{C}), 21.46\left(2 \times \mathrm{CH}_{3}\right), 16.92$ (11-C), 4.98 (12- and 13-CH $)$; IR : 3401, 3074, 2994, 2917, 2855, 1719, 1577, 1542, 1419, 1240, 1089, $791 \mathrm{~cm}^{-1}$; LC-MS, positive mode: 315 (M+H)+; purity: $95.2 \%$. HRMS (ESI-TOF) $m / z$ : for $\left(\mathrm{C}_{22} \mathrm{H}_{23} \mathrm{~N}_{2}\right.$; $\left.\mathrm{Na}=\mathrm{C}_{22} \mathrm{H}_{22} \mathrm{~N}_{2} \mathrm{Na}^{+}\right)$calcd: 337.1681 Found 337.1675.

(Cyclohexyl)di-(5-fluoro-1H-indol-3-yl)methane (8w). 5-Fluoroindole (6e, 0.5g, $3.6 \mathrm{mmol}$ ) was treated with cyclohexanecarboxaldehyde (7I, $0.219 \mathrm{~mL}, 1.8 \mathrm{mmol}, 0.5$ equiv.) in the presence of concentrated sulfuric acid $(0.196 \mathrm{~mL}, 3.6 \mathrm{mmol})$ in water $(5.0 \mathrm{~mL})$. Brown viscous oil; yield: 87\%; ${ }^{1} \mathrm{H}$ NMR (500 MHz, DMSO- $\left.d_{6}\right) \delta 10.80(\mathrm{~d}$, $J=2.5 \mathrm{~Hz}, 2 \mathrm{H}, 2 \times \mathrm{NH}), 7.41$ (d, $\left.J=2.5 \mathrm{~Hz}, 2 \mathrm{H}, 2-\mathrm{H}, 2^{\prime}-\mathrm{H}\right), 7.29$ (dd, J=10.4, $\left.2.6 \mathrm{~Hz}, 2 \mathrm{H}, 7-\mathrm{H}, 7^{\prime}-\mathrm{H}\right), 7.24(\mathrm{dd}, J=$ 8.8, 4.6 Hz, 2H, 4-H, 4'-H), $6.80\left(\mathrm{td}, J=9.1,2.6 \mathrm{~Hz}, 2 \mathrm{H}, 6-\mathrm{H}, 6^{\prime}-\mathrm{H}\right), 4.04-3.98(\mathrm{~m}, 1 \mathrm{H}, 10-\mathrm{H}), 2.24(\mathrm{td}, J=11.0$, $7.6 \mathrm{~Hz}, 1 \mathrm{H}, 11-\mathrm{H}), 1.77-1.52\left(\mathrm{~m}, 2 \mathrm{H}, \mathrm{cychex}-\mathrm{CH}_{2}\right), 1.53-1.34(\mathrm{~m}, 1 \mathrm{H}, \mathrm{cychex}-\mathrm{CH}), 1.33-1.18(\mathrm{~m}, 2 \mathrm{H}, \mathrm{cychex}-$ $\left.\mathrm{CH}_{2} \&-\mathrm{CH}\right), 0.97-0.68\left(\mathrm{~m}, 4 \mathrm{H}, 2 \times\right.$ cychex- $\left.\mathrm{CH}_{2}\right) ;{ }^{13} \mathrm{C}$ NMR $\left(126 \mathrm{MHz}, \mathrm{DMSO}-d_{6}\right) \delta 157.44\left(5-\mathrm{C}, 5^{\prime}-\mathrm{C}\right), 132.93(9-\mathrm{C}$, $\left.9^{\prime}-C\right), 132.93\left(8-C, 8^{\prime}-C\right), 127.46,\left(2-C, 2^{\prime}-C\right), 124.51$ (6-C, 6'-C), 112.10 (3-C, 3'-C), 108.57 (7-C, 7'-C), 103.58 (4C, 4'-C), 59.07 (10-C), 31.91 (11-C), 26.01 ( 2 x cychex-C), 14.21 (3 x cychex-C); IR : 3467, 3421, 2922, 2849, $1716,1626,1578,1482,1374,1168,936,794 \mathrm{~cm}^{-1}$; LC-MS, positive mode $360(\mathrm{M}+\mathrm{H})^{+}$; purity: 95.5\%. HRMS (ESI-TOF) $m / z$ : for $\left(\mathrm{C}_{23} \mathrm{H}_{23} \mathrm{~F}_{2} \mathrm{~N}_{2}[\mathrm{M}+\mathrm{H}]^{+}\right)$calcd: 365.1829 Found 365.1824.

Methyl 5,5-di-(4-fluoro-1H-indol-3-yl)butanoate (8x). 4-Fluoroindole (6f, 0.5g, $3.6 \mathrm{mmol})$ was treated with 4-oxobutanoic acid methyl ester $(7 \mathrm{~m}, 0.209 \mathrm{~mL}, 1.8 \mathrm{mmol}, 0.5$ equiv.) in the presence of concentrated sulfuric acid $(0.196 \mathrm{~mL}, 3.6 \mathrm{mmol})$ in water $(5.0 \mathrm{~mL})$. White solid; m.p. $147-149{ }^{\circ} \mathrm{C}$; yield: $56 \%$; ${ }^{1} \mathrm{H} \mathrm{NMR}(500 \mathrm{MHz}$, DMSO-d6) $\delta 11.05$ (s, 2H, $2 \times \mathrm{NH}), 7.14\left(\mathrm{~d}, J=8.1 \mathrm{~Hz}, 2 \mathrm{H}, 6-\mathrm{H}, 6^{\prime}-\mathrm{H}\right), 7.04\left(\mathrm{~d}, J=2.4 \mathrm{~Hz}, 2 \mathrm{H}, 2-\mathrm{H}, 2^{\prime}-\mathrm{H}\right), 6.97$ (td, J $\left.=7.9,4.9 \mathrm{~Hz}, 2 \mathrm{H}, 5-\mathrm{H}, 5^{\prime}-\mathrm{H}\right), 6.68-6.60\left(\mathrm{~m}, 2 \mathrm{H}, 7-\mathrm{H}, 7^{\prime}-\mathrm{H}\right), 4.70(\mathrm{t}, J=6.8 \mathrm{~Hz}, 1 \mathrm{H}, 10-\mathrm{H}), 3.50\left(\mathrm{~s}, 3 \mathrm{H}, \mathrm{COOCH}_{3}\right)$, $2.39-2.28\left(\mathrm{~m}, 4 \mathrm{H}, 12-\mathrm{CH}_{2}\right.$ and $\left.11-\mathrm{CH}_{2}\right) ;{ }^{13} \mathrm{C}$ NMR (126 MHz, DMSO-d6) $\delta 173.34(\mathrm{COOH}), 157.45\left(4-\mathrm{C}, 4^{\prime}-\mathrm{C}\right)$, 155.51 (9-C, 9'-C), 139.37 (2-C, 2'-C), 122.85 (6-C, 6'-C), 121.41 (8-C, 8'-C), 121.35 (5-C, 5'-C), 117.45 (7-C, 7'-C), 108.07 (3-C, 3'-C), $103.62(10-C), 51.21\left(\mathrm{COOCH}_{3}\right), 34.17(11-\mathrm{C}), 32.69$ (121-C); IR : 3395, 3331, 2959, 2923, $2851,2310,1748,1695,1503,1435,1253,1031,777 \mathrm{~cm}^{-1}$; LC-MS, positive mode: $386\left(\mathrm{M}+\mathrm{H}_{2} \mathrm{O}\right)^{18+}$; purity: 96.2\%. HRMS (ESI-TOF) $\mathrm{m} / \mathrm{z}$ : for $\left(\mathrm{C}_{21} \mathrm{H}_{18} \mathrm{~F}_{2} \mathrm{~N}_{2} \mathrm{O}_{2} ; \mathrm{NH}_{4}=\mathrm{C}_{21} \mathrm{H}_{2}{ }^{\prime \prime} \mathrm{F}_{2} \mathrm{~N}_{3} \mathrm{O}_{2}{ }^{+}\right)$calcd: 386.1680 Found calcd: 386.1675.

\section{Synthesis of 5,5-di-(4-fluoro-1H-indol-3-yl)butanoic acid (8y)}

To a solution of methyl 5,5-di-(4-fluoro- $1 \mathrm{H}$-indol-3-yl)pentanoate $(\mathbf{8 x}, 50 \mathrm{mg})$ in ethanol $(10 \mathrm{~mL}) 2 \mathrm{~N} \mathrm{NaOH}(5$ $\mathrm{mL}$ ) was added and the mixture was refluxed for $1 \mathrm{~h}$. After cooling the mixture, the ethanol was evaporated under reduced pressure. The resulting residue was dissolved in water and acidified with $6 \mathrm{~N} \mathrm{HCl}$ to $\mathrm{pH} \leq 1$. The precipitated solid was filtered off, washed with water and dried at room temperature for $24 \mathrm{~h}$. White solid; m.p. $169-171{ }^{\circ} \mathrm{C}$; yield: 97\%; ${ }^{1} \mathrm{H}$ NMR $\left(500 \mathrm{MHz}, \mathrm{DMSO}-d_{6}\right) \delta 11.88(\mathrm{~s}, 1 \mathrm{H}, \mathrm{COOH}), 11.05$ (s, 2H, $\left.2 \times \mathrm{NH}\right), 7.14(\mathrm{~d}$, $\left.J=8.2 \mathrm{~Hz}, 2 \mathrm{H}, 6-\mathrm{H}, 6^{\prime}-\mathrm{H}\right), 7.04\left(\mathrm{~d}, J=2.4 \mathrm{~Hz}, 2 \mathrm{H}, 2-\mathrm{H}, 2^{\prime}-\mathrm{H}\right), 6.97\left(\mathrm{td}, J=8.0,4.9 \mathrm{~Hz}, 2 \mathrm{H}, 5-\mathrm{H}, 5^{\prime}-\mathrm{H}\right), 6.64(\mathrm{dd}, J=$ 11.6, 7.7 Hz, 2H, 7-H, 7'-H), 4.69 (t, $J=7.4 \mathrm{~Hz}, 1 \mathrm{H}, 10-\mathrm{H}$ ), 2.31 (q, J=7.5 Hz, 2H, 12-CH $\mathrm{CH}_{2}, 2.23$ (dd, J=8.5, 6.0 $\left.\mathrm{Hz}, 2 \mathrm{H}, 11-\mathrm{CH}_{2}\right) ;{ }^{13} \mathrm{C}$ NMR (126 MHz, DMSO-d $)_{6} \delta 174.51(\mathrm{COOH}), 157.46\left(4-\mathrm{C}, 4^{\prime}-\mathrm{C}\right), 155.52,\left(9-\mathrm{C}, 9^{\prime}-\mathrm{C}\right), 139.47$ (2-C, 2'-C), 122.79 (6-C, 6'-C), 121.38 (8-C, 8'-C), 121.32, (5-C, 5'-C) 117.67 (7-C, 7'-C), 108.06 (3-C, 3'-C), 103.60 (10-C), 34.22 (11-C), 33.00 (12-C); IR : 3440, 3340, 2994, 2922, 2853, 1685, 1578, 1507, 1348, 1221, 1031, 908, $730 \mathrm{~cm}^{-1}$; LC-MS, positive mode: $355(\mathrm{M}+\mathrm{H})^{+}$; purity: 96.3\%. HRMS (ESI-TOF) $\mathrm{m} / \mathrm{z}$ : for $\left(\mathrm{C}_{20} \mathrm{H}_{16} \mathrm{~F}_{2} \mathrm{~N}_{2} \mathrm{O}_{2} ; \mathrm{NH}_{4}=\right.$ $\mathrm{C}_{20} \mathrm{H}_{20} \mathrm{~F}_{2} \mathrm{~N}_{3} \mathrm{O}_{2}{ }^{+}$) calcd: 372.1518 Found calcd: 372.1518 . 


\section{Acknowledgements}

T. P. is indebted to the Alexander von Humboldt foundation for a post-doctoral fellowship. C.E.M., D.M. and H.I. were supported by the DAAD (Projekt-ID 57143280: International Master of Science in Drug Research).

\section{Supplementary Material}

Characterization data (for all new products), copies of ${ }^{1} \mathrm{H}$ and ${ }^{13} \mathrm{C} N M R, \mathrm{HRMS}$ and IR spectra associated with this paper.

\section{References}

1. Samala, S.; Arigela, R. K.; Kant, R.; Kundu, B. J. Org. Chem. 2014, 79, 2491-2500. https://doi/pdf/10.1021/jo400799b

2. Patil, S. A.; Patil, R. D. D. Future Med. Chem. 2012, 4, 2085-2115. https://doi.org/10.4155/fmc.12.141

3. Cho, S. D.; Yoon, K.; Chintharlapalli, S.; Abdelrahim, M.; Lei, P.; Hamilton, S.; Khan, S.; Ramaiah, S. K.; Safe, S. Cancer Res. 2007, 67, 674-683. https://doi.org/10.1124/mol.109.061143

4. Morris, S. A.; Anderson, R. J. Tetrahedron 1990, 46, 715-720. https://doi.org/10.1016/S0040-4020(01)81355-7

5. Bifulco, G.; Bruno, I.; Riccio, R.; Lavayre, J.; Bourdy, G. J. Nat. Prod. 1995, 58, $1254-1260$. https://doi/abs/10.1021/np50122a017

6. Bell, R.; Carmeli, S.; Sar, N. J. Nat. Prod. 1994, 57, 1587-1590. https://doi/abs/10.1021/np50113a022

7. Sivaprasad, G.; Perumal, P. T.; Prabavathy, V. R.; Mathivanan, N. Bioorg. Med. Chem. Lett. 2006, 16, 63026305.

http://www.sciencedirect.com/science/article/pii/S0960894X06010638?via\%3Dihub

8. Kamal, A.; Khan, M. N. A.; Srinivasa, R. K.; Srikanth, Y. V. V.; Kaleem, A. S.; Pranay, K. K.; Murthy, U. S. N. J. Enzyme Inhib. Med. Chem. 2009, 24, 559-565. http://dx.doi.org/10.1080/14756360802292974

9. Chen, I.; McDougal, A.; Wang, F.; Safe, S. Carcinogenesis 1998, 19, 1631-1639.

10. Kobayashi, M.; Aoki, S.; Gato, K.; Matsunami, K.; Kurosu, M.; Kitagawa, I. Chem. Pharm. Bull (Tokyo). 1994, 42, 2449-2451.

https://www.jstage.jst.go.jp/article/cpb1958/42/12/42 12 2449/ article

11. Krämer, H. J:, Podobinska, M.; Bartsch, A.; Battmann, A.; Thoma, W.; Bernd, A.; Kummer, W.; Irlinger, B.; Steglich, W.; Mayser, P. Chembiochem. 2005, 6, 860-865. http://www.wiley-vch.de/contents/jc 2268/2005/f400247 s.pdf

12. Quintana, F. J.; Basso, A. S.; Iglesias, A. H.; Korn, T.; Farez, M. F.; Bettelli, E.; Caccamo, M.; Oukka,M.; Weiner, H. L. Nature 2008, 453, 65-71.

https://www.nature.com/nature/journal/v453/n7191/full/nature06880.html 
13. Anderton, M. J.; Manson, M. M.; Verschoyle, R.; Gescher, A.; Lamb, J. H.; Farmer, P. B.; Steward, W. P.; Williams, M. L. Clin. Cancer Res. 2004, 10, 5233-5241.

http://clincancerres.aacrjournals.org/content/10/15/5233.long

14. Zhang, W. W.; Feng, Z.; Narod, S. A. J. Biomed. Res. 2014, 28, 339-348.

https://www.ncbi.nlm.nih.gov/pmc/articles/PMC4197384/pdf/ibr-28-05-339.pdf

15. Maciejewska, D.; Rasztawicka, M.; Wolska, I.; Anuszewska, E.; Gruber, B. Eur. J. Med. Chem. 2009, 44, 4136-4147.

https://doi.org/10.1016/j.ejmech.2009.05.011

16. Kim, S. M. Int. J. Mol. Sci. 2016, 19, 17, 1155.

http://www.mdpi.com/1422-0067/17/7/1155

17. Kunimasa, K.; Kobayashi, T.; Kaji, K. Ohta, T. J. Nutr. 2010, 140, 1-6.

http://in.nutrition.org/content/140/1/1.long

18. Xue, L.; Firestone, G. L.; Bjeldanes, L. F. Oncogene 2005, 24, 2343-2353.

http://www.nature.com/onc/journal/v24/n14/abs/1208434a.html

19. Cho, H. J.; Seon, M. R.; Lee, Y. M.; Kim, J.; Kim, J. K.; Kim, S. G.; Park, J. H. J. Nutr. 2008, 138, 17-23.

20. Zong, J.; Wu, Q. Q.; Zhou, H.; Zhang, J. Y.; Yuan, Y.; Bian, Z. Y.; Deng, W.; Dai, J.; Li, FF.; Xu, M.; Fang, Y.; Tang, Q. Z. Mol. Med. Rep. 2015, 12, 1247-1252.

https://doi.org/10.3892/mmr.2015.3523

21. Jayakumar, P.; Pugalendi, K. V.; Sankaran, M. J. Physiol. Biochem. 2014, 70, 525-534.

https://link.springer.com/article/10.1007/s13105-014-0332-5

22. Yin, X. F.; Chen, J.; Mao, W.; Wang, Y. H.; Chen, M. H. J. Exp. Clin. Cancer. Res. 2012, 31, 31-46.

https://jeccr.biomedcentral.com/articles/10.1186/1756-9966-31-46

23. Busbee, P. B.; Nagarkatti, M.; Nagarkatti, P. S. Toxicol Appl Pharmacol. 2014, 274, 7-16.

https://doi.org/10.1016/j.taap.2013.10.022

24. Takeda, S.; Yamamoto, A.; Okada, T.; Matsumura, E.; Nose, E.; Kogure, K.; Kojima, S.; Haga, T. Life Sci. 2003, 74, 367-377.

https://doi.org/10.1016/j.Ifs.2003.09.030

25. Pillaiyar, T.; Köse, M.; Sylvester, K.; Thimm, D.; Borges, G.; von Kügelgen, I.; Müller, C. E. J. Med. Chem. 2017, 60, 3636-3655.

http://pubs.acs.org/doi/abs/10.1021/acs.jmedchem.6b01593

26. Shiri M1, Zolfigol MA, Kruger HG, Tanbakouchian Z. Chem. Rev. 2010, 110, 2250-2293.

http://pubs.acs.org/doi/abs/10.1021/cr900195a

27. Kaishap, P.P.; Dohutia, C. IJPSR, 2013, 4, 1312-1322.

http://dx.doi.org/10.13040/IJPSR.0975-8232.4(4).1312-22

28. Chakrabarty, M.; Ghosh, N.; Basak, R.; Harigaya, Y. Tetrahedron Lett. 2002, 43, 4075-4078. https://doi.org/10.1016/j.arabjc.2011.02.009

29. Li, J.; Zhou, M.; Li, B.-G.; Zhang, G.-L. Synth. Commun. 2004, 34, 275-280.

http://dx.doi.org/10.1080/00397910802604224

30. Mallik, A. K.; Pal, R.; Guha, C.; Mallik, H. Green Chem. Lett. Rev. 2012, 5, 321-327.

http://dx.doi.org/10.1080/17518253.2011.630027

31. Deb, M. L.; Bhuyan, P. J. Tetrahedron Lett. 2006, 47, 1441-1443.

https://doi.org/10.1016/i.tetlet.2005.12.093

32. Ghorbani-Vaghei, R.; Veisi, H.; Keypour, H.; Dehghani-Firouzabadi, A. A. Mol. Divers. 2010, 14, 87-96. https://link.springer.com/article/10.1007/s11030-009-9150-z 
33. Nobuta, T.; Fujiya, A.; Tada, N.; Miura, T.; Itoh, A. Synlett. 2012, 23, 2975-2979. https://doi.org/10.1016/i.tetlet.2013.10.143

34. Putra, A. E.; Takigawa, K.; Tanaka, H.; Ito, Y.; Oe, Y.; Ohta, T. Eur. J. Org. Chem. 2013, 6344-6354. http://onlinelibrary.wiley.com/doi/10.1002/ejoc.201300744/epdf

35. Babu, G.; Sridhar, N.; Perumal, P. T. Synth. Commun. 2000, 30, 1609-1614. http://dx.doi.org/10.1080/00397910008087197

36. Chakraborti, A. K.; Roy, S. R.; Kumar, D.; Chopra, P. Green Chem. 2008, 10, 1111-1118.

37. http://pubs.rsc.org/en/content/articlepdf/2008/gc/b807572g

38. Yadav, J. S.; Reddy, B. V. S.; Sunitha, S. Adv. Synth. Catal. 2003, 345, 349-352. http://onlinelibrary.wiley.com/doi/10.1002/adsc.200390038/full

39. Bandgar, B. P.; Shaikh, K. A. J. Chem. Res. Synop. 2004, 34.

40. Xia, M.; Wang, S. h.; Yuan, W. b. Synth. Commun. 2004, 34, 3175-3182.

41. http://dx.doi.org/10.1081/SCC-200028611

42. Ramshini, H.; Mannini, B.; Khodayari, K.; Ebrahim-Habibi, A.; Moghaddasi, A.S.; Tayebee, R.; Chiti, F. Eur. J. Med. Chem. 2016, 124, 361-371.

43. https://doi.org/10.1016/i.ejmech.2016.08.056

44. Auria, M. Tetrahedron 1991, 47, 9225-9230. https://doi.org/10.1016/S0040-4020(01)96210-6

45. Yang, J.; Wang, Z.; Pan, F.; Li, Y.; Bao, W. Org. Biomol. Chem. 2010, 8, 2975-2988.

46. Abe, T.; Nakamura, S.; Yanada, R.; Choshi, T.; Hibino, S.; Ishikura, M. Org. Lett. 2013, 15, 3622-3625. http://pubs.acs.org/doi/abs/10.1021/ol034851y

47. Gopalaiah, K.; Naga Chandrudu, S.; Devi. A. Synthesis 2015, 47, 1766-1774. https://www.thieme-connect.com/products/ejournals/pdf/10.1055/s-0034-1380012.pdf

48. Veluri, R.; Oka, I.; Wagner-Döbler, I.; Laatsch, H. J. Nat. Prod. 2003, 66, 1520-1523. http://pubs.acs.org/doi/abs/10.1021/np030288g

49. Ramesh, C.; Banerjee, J.; Pal, R.; Das, B. Adv. Synth. Catal. 2003, 345, 557-559.

50. Khalafi-Nezhad, A.; Parhamia, A.; Zareb, A.; Moosavi Zarea, A. R.; Hasaninejadc, A.; Panahia F. Synthesis 2008, 4, 617-621.

https://www.thieme-connect.com/products/ejournals/html/10.1055/s-2008-1032159

51. Chen, D.; Yu, L.; Wang, P.G. Tetrahedron Lett. 1996, 37, 4467-4470.

52. Yadav, J. S.; Reddy, B. V. S.; Murthy, V. S. R.; Mahesh K. G.; Madan, C. Synthesis 2001, 783-787. https://www.thieme-connect.de/DOI/DOI?10.1055/s-2001-12777

53. Beltrá, J.; Gimeno, M. C.; Herrera, R. P. Beilstein J. Org. Chem. 2014, 10, 2206-2214. http://www.beilstein-journals.org/bjoc/articles/10/228 